Acta Crystallographica Section B

Structural

Science

ISSN 0108-7681

\section{Silvia Cuffini, ${ }^{a}$ Christopher} Glidewell, $^{b_{*}}$ John N. Low, Aline G. de Oliveira,

Marcus V. N. de Souza, ${ }^{\text {d }}$

Thatyana R. A. Vasconcelos, ${ }^{d}$

Solange M. S. V. Wardell ${ }^{d}$ and

James L. Wardell ${ }^{\mathrm{e}}$

aAgência Córdoba Ciência-Unidad Ceprocor, Córdoba, Argentina, 'bschool of Chemistry, University of St Andrews, St Andrews, Fife KY16 9ST, Scotland, 'Department of Chemistry, University of Aberdeen, Meston Walk, Old Aberdeen AB24 3UE, Scotland, ${ }^{\mathbf{d}}$ Fundação Oswaldo Cruz, Far Manguinhos, Rua Sizenando Nabuco, 100 Manguinhos, 21041-250 Rio de Janeiro-RJ, Brazil, and $\mathbf{e}$ Instituto de Química, Departamento de Química Inorgânica, Universidade Federal do Rio de Janeiro, CP 68563, 21945-970 Rio de Janeiro-RJ, Brazil

Correspondence e-mail: cg@st-andrews.ac.uk

(C) 2006 International Union of Crystallography

Printed in Great Britain - all rights reserved

\title{
Nine $\mathrm{N}$-aryl-2-chloronicotinamides: supramolecular structures in one, two and three dimensions
}

Structures are reported here for eight further substituted $\mathrm{N}$ aryl-2-chloronicotinamides, $2-\mathrm{ClC}_{5} \mathrm{H}_{3} \mathrm{NCONHC}_{6} \mathrm{H}_{4} X-4^{\prime}$. When $X=\mathrm{H}$, compound (I) $\left(\mathrm{C}_{12} \mathrm{H}_{9} \mathrm{ClN}_{2} \mathrm{O}\right)$, the molecules are linked into sheets by $\mathrm{N}-\mathrm{H} \cdots \mathrm{N}, \mathrm{C}-\mathrm{H} \cdots \pi$ (pyridyl) and $\mathrm{C}-\mathrm{H} \cdots \pi$ (arene) hydrogen bonds. For $X=\mathrm{CH}_{3}$, compound (II) $\left(\mathrm{C}_{13} \mathrm{H}_{11} \mathrm{ClN}_{2} \mathrm{O}\right.$, triclinic $P \overline{1}$ with $\left.Z^{\prime}=2\right)$, the molecules are linked into sheets by $\mathrm{N}-\mathrm{H} \cdots \mathrm{O}, \mathrm{C}-\mathrm{H} \cdots \mathrm{O}$ and $\mathrm{C}-$ $\mathrm{H} \cdots \pi$ (arene) hydrogen bonds. Compound (III), where $X=$ $\mathrm{F}$, crystallizes as a monohydrate $\left(\mathrm{C}_{12} \mathrm{H}_{8} \mathrm{ClFN}_{2} \mathrm{O} \cdot \mathrm{H}_{2} \mathrm{O}\right)$ and sheets are formed by $\mathrm{N}-\mathrm{H} \cdots \mathrm{O}, \mathrm{O}-\mathrm{H} \cdots \mathrm{O}$ and $\mathrm{O}-\mathrm{H} \cdots \mathrm{N}$ hydrogen bonds and aromatic $\pi \cdots \pi$ stacking interactions. Crystals of compound (IV), where $X=\mathrm{Cl}\left(\mathrm{C}_{12} \mathrm{H}_{8} \mathrm{Cl}_{2} \mathrm{~N}_{2} \mathrm{O}\right.$, monoclinic $P 2_{1}$ with $Z^{\prime}=4$ ) exhibit inversion twinning: the molecules are linked by $\mathrm{N}-\mathrm{H} \cdots \mathrm{O}$ hydrogen bonds into four independent chains, linked in pairs by $\mathrm{C}-\mathrm{H} \cdots \pi$ (arene) hydrogen bonds. When $X=\mathrm{Br}$, compound (V) $\left(\mathrm{C}_{12} \mathrm{H}_{8} \mathrm{BrClN}_{2} \mathrm{O}\right)$, the molecules are linked into sheets by $\mathrm{N}-\mathrm{H} \cdots \mathrm{O}$ and $\mathrm{C}-\mathrm{H} \cdots \mathrm{N}$ hydrogen bonds, while in compound (VI), where $X=\mathrm{I}\left(\mathrm{C}_{12} \mathrm{H}_{8} \mathrm{CIIN}_{2} \mathrm{O}\right)$, the molecules are linked into a three-dimensional framework by $\mathrm{N}-\mathrm{H} \cdots \mathrm{O}$ and $\mathrm{C}-\mathrm{H} \cdots \pi($ arene $)$ hydrogen bonds and an iodo $\cdots \mathrm{N}$ (pyridyl) interaction. For $X=\mathrm{CH}_{3} \mathrm{O}$, compound (VII) $\left(\mathrm{C}_{13} \mathrm{H}_{11} \mathrm{ClN}_{2} \mathrm{O}_{2}\right)$, the molecules are linked into chains by a single $\mathrm{N}-\mathrm{H} \cdots \mathrm{O}$ hydrogen bond. Compound (VIII) $\left(\mathrm{C}_{13} \mathrm{H}_{8} \mathrm{ClN}_{3} \mathrm{O}\right.$, triclinic $P \overline{1}$ with $\left.Z^{\prime}=2\right)$, where $X=\mathrm{CN}$, forms a complex three-dimensional framework by $\mathrm{N}-\mathrm{H} \cdots \mathrm{N}, \mathrm{C}-$ $\mathrm{H} \cdots \mathrm{N}$ and $\mathrm{C}-\mathrm{H} \cdots \mathrm{O}$ hydrogen bonds and two independent aromatic $\pi \cdots \pi$ stacking interactions.

\section{Introduction}

Nicotinic acid (pyridine-3-carboxylic acid) and nicotinamide (niacinamide, pyridine-3-carboxamide) are two of the principal members of the B-vitamin complex. Niacin, nicotinamide and nicotinic acid have identical vitamin activities, but they have very different pharmacological activities. Nicotinamide, via its major metabolite nicotinamide adenine dinucleotide, is involved in a wide range of biological processes including the production of energy, the synthesis of fatty acids, cholesterol and steroids, signal transduction, and the maintenance of the integrity of the genome. Nicotinic acid in pharmacological doses is used as an antihyperlipidemic agent: it also causes vasodilation of cutaneous blood vessels. Nicotinamide has been investigated as an agent for the prevention or delay of the onset of type 1 diabetes mellitus. It also has anti-oxidant, anti-inflammatory and anti-carcinogenic activities, and has putative activity against osteoarthritis and granuloma annulare. We have made a study of the properties and activities of substituted derivatives, 2-chloro- $N$-(4- $X$-phenyl)nicotina-
Received 28 January 2006 Accepted 27 April 2006 
mides, and here we report the structures and supramolecular arrangements of nine examples having $X=\mathrm{H}$ (I), Me (II), F (III), $\mathrm{Cl}$ (IV), Br (V), I (VI), OMe (VII) and CN (VIII), and including the recently reported analogue with $X=\mathrm{NO}_{2}$, (IX) (de Souza et al., 2005).

Here we report the molecular and supramolecular structures of eight closely related $\mathrm{N}$-aryl-2-chloronicotinamides, 2$\mathrm{ClC}_{5} \mathrm{H}_{3} \mathrm{NCONHC}_{6} \mathrm{H}_{4} X-4^{\prime}$, whose crystallization characteristics prove to be all different, even within the halogensubstituted subset, (III)-(VI), and whose supramolecular structures all prove to be different, with no two utilizing the same combination of direction-specific intermolecular interactions.

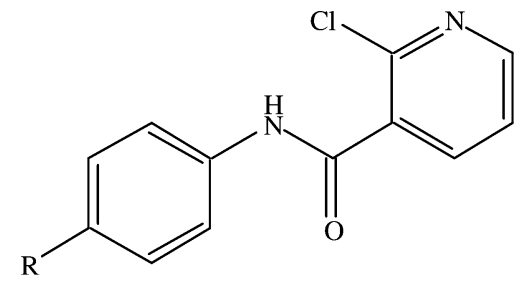

$$
\begin{aligned}
& \text { (I) } \mathrm{R}=\mathrm{H} \\
& \text { (II) } \mathrm{R}=\mathrm{CH}_{3} \\
& \text { (III) } \mathrm{R}=\mathrm{F} \\
& \text { (IV) } \mathrm{R}=\mathrm{Cl} \\
& \text { (V) } \mathrm{R}=\mathrm{Br} \\
& \text { (VI) } \mathrm{R}=\mathrm{I} \\
& \text { (VII) } \mathrm{R}=\mathrm{OCH}_{3} \\
& \text { (VIII) } \mathrm{R}=\mathrm{CN} \\
& \text { (IX) } \mathrm{R}=\mathrm{NO}_{2}
\end{aligned}
$$

\section{Experimental}

\subsection{Synthesis}

Samples of (I)-(VIII) were prepared by reaction of equimolar quantities of 2-chloronicotinoyl chloride and the appropriate substituted aniline in tetrahydrofuran solution at ambient temperature in the presence of a catalytic quantity of triethylamine. After stirring for $8 \mathrm{~h}$, the reaction mixtures were neutralized with saturated aqueous sodium hydrogencarbonate solution and the resulting aqueous mixtures were extracted with ethyl acetate $\left(2 \times 30 \mathrm{~cm}^{3}\right)$. For each preparation, the organic extracts were combined, dried over anhydrous sodium sulfate, and then concentrated under reduced pressure. Chromatography on silica, using hexane:ethyl acetate gradients (up to $50 \%$ ethyl acetate), then yielded the pure products, with yields in the range $80-90 \%$. Crystals of (I), (II) and (IV)-(VIII) suitable for single-crystal X-ray diffraction were grown from solution in ethanol, and crystals of (III) were grown from an aqueous solution: m.p.s: (I) 395-397 K, (II) 432-433 K, (III) 366-367 K, (IV) 421-422 K, (V) 399$400 \mathrm{~K}$, (VI) 448-450 K, (VII) 383-384 K and (VIII) 445$446 \mathrm{~K}$.

\subsection{Data collection, structure solution and refinement}

Details of cell data, data collection and structure solution and refinement are summarized in Table 1 (Bruker, 2004; Cernik et al., 1997; Ferguson, 1999; McArdle, 2003; Otwinowski \& Minor, 1997; Sheldrick, 1997a,b, 2003; Hooft, 1999). The space groups for (I), (IV), (V), VI) and (VII) were all assigned uniquely from the systematic absences: crystals of (II), (III) and (VIII) are triclinic, and for each the space group $P \overline{1}$ was selected, and confirmed by the successful structure analysis. The structures were all solved by direct methods using SHELXS97 (Sheldrick, 1997a) and refined on $F^{2}$ with all data using SHELXL97 (Sheldrick, 1997b). A weighting scheme based upon $P=\left[F_{o}^{2}+2 F_{c}^{2}\right] / 3$ was employed in order to reduce statistical bias (Wilson, 1976). All $\mathrm{H}$ atoms were located from difference maps and all were included in the refinements as riding atoms, with distances $\mathrm{C}-\mathrm{H} 0.95$ and $\mathrm{N}-$ $\mathrm{H} 0.88 \AA$, and with $U_{\text {iso }}(\mathrm{H})=1.2 U_{\text {eq }}(\mathrm{C}, \mathrm{N})$. For $(\mathrm{V})$ and $(\mathrm{VII})$, the correct enantiomorph was selected using the Flack parameter (Flack, 1983): the final values were 0.031 (7) and -0.05 (7), respectively. For (IV), where the crystals were all of very poor quality, the Flack parameter 0.54 (11) indicated inversion twinning.

Supramolecular analyses were made and the diagrams were prepared with the aid of PLATON (Spek, 2003). Figs. 1-30 show the independent components of (I)-(VIII) and aspects of their supramolecular structures. Selected torsional angles are given in Table 2 and details of the hydrogen bonding are in Table 3. ${ }^{1}$

\section{Results and discussion}

\subsection{Crystallization characteristics}

Compounds (II) and (VIII) both crystallize with $Z^{\prime}=2$, while (IV) has $Z^{\prime}=4$; similarly, the 4-nitrophenyl derivative (IX) crystallizes with $Z^{\prime}=2$ (de Souza et al., 2005). Of the compounds (I)-(VIII) reported here, the 4-fluorophenyl derivative is unique in crystallizing as a monohydrate, although the 2-nitrophenyl analogue reported recently (de Souza et al., 2005) also crystallizes as a stoichiometric monohydrate.

\subsection{Molecular conformations}

In each of compounds (I)-(VIII), as well as in (IX) (de Souza et al., 2005), the central $\mathrm{C}-\mathrm{C}-\mathrm{N}-\mathrm{C}$ spacer unit is nearly planar, as shown by the torsional angles for this unit which are all close to $180^{\circ}$, ranging between 170.0 (3) and $-173.4(2)^{\circ}$ (Table 2). However, the aryl ring is often markedly twisted out of this plane, particularly in (II), (IV), (V), (VI) and (VII), while the chloropyridyl is always twisted well away from the plane of the central spacer, being nearly orthogonal to this plane in (II), (VI), (VIII) and (IX). An alternative way to consider the overall conformations is by

\footnotetext{
${ }^{1}$ Supplementary data for this paper are available from the IUCr electronic archives (Reference: BM5033). Services for accessing these data are described at the back of the journal.
} 
Table 1

Experimental details.

(I) (II) $\quad$ (III)

Crystal data

Chemical formula

$M_{r}$

Cell setting, space group

Temperature (K)

$a, b, c(\AA)$

$\alpha, \beta, \gamma\left(^{\circ}\right)$

$V\left(\AA^{3}\right)$

$Z$

$D_{x}\left(\mathrm{Mg} \mathrm{m}^{-3}\right)$

Radiation type

No. of reflections for cell parameters

$\theta$ range $\left({ }^{\circ}\right)$

$\mu\left(\mathrm{mm}^{-1}\right)$

Crystal form, colour

Crystal size (mm)

Data collection

Diffractometer

Data collection method

Absorption correction

$T_{\min }$
$T_{\max }$

No. of measured, independent and observed reflections

Criterion for observed reflections

$R_{\text {int }}$

$\theta_{\max }\left({ }^{\circ}\right)$

Range of $h, k, l$

Refinement

Refinement on

$R\left[F^{2}>2 \sigma\left(F^{2}\right)\right], w R\left(F^{2}\right), S$

No. of reflections

No. of parameters

$\mathrm{H}$-atom treatment

Weighting scheme

$(\Delta / \sigma)_{\max }$

$\Delta \rho_{\max }, \Delta \rho_{\min }\left(\mathrm{e} \AA^{-3}\right)$

Absolute structure

Flack parameter

\section{$\mathrm{C}_{12} \mathrm{H}_{9} \mathrm{ClN}_{2} \mathrm{O}$ \\ 232.66 \\ Orthorhombic, Pccn \\ $120(2)$ \\ 13.2296 (6), 21.0744 (10), \\ 7.6898 (16) \\ 90, 90,90}

$2144.0(5)$

8

1.442

Mo $K \alpha$

2446

$3.1-27.5$

0.33

Needle, colourless

$0.24 \times 0.09 \times 0.02$

Bruker-Nonius $95 \mathrm{~mm} \mathrm{CCD}$ camera on $\kappa$ goniostat

$\varphi$ and $\omega$ scans

Multi-scan

0.943

0.993

$17837,2446,1724$

$I>2 \sigma(I)$

0.104

27.5

$-16 \Rightarrow h \Rightarrow 17$

$-27 \Rightarrow k \Rightarrow 27$

$-9 \Rightarrow l \Rightarrow 9$

$F^{2}$

$0.059,0.129,1.07$

2446

145

Constrained to parent site

$w=1 /\left[\sigma^{2}\left(F_{o}^{2}\right)+(0.0479 P)^{2}+\right.$ 1.6007P], where $P=\left(F_{o}^{2}+\right.$ $\left.2 F_{c}^{2}\right) / 3$

0.001

$0.28,-0.28$

$-$

$\begin{array}{ll}\mathrm{C}_{13} \mathrm{H}_{11} \mathrm{ClN}_{2} \mathrm{O} & \mathrm{C}_{12} \mathrm{H}_{8} \mathrm{ClFN}_{2} \mathrm{O} \cdot \mathrm{H}_{2} \mathrm{O} \\ 246.69 & 268.67 \\ \text { Triclinic, } P \overline{1} & \text { Triclinic, } P \overline{1} \\ 120(2) & 120(2) \\ 9.6824(6), 11.3082(7), & 6.8033(4), 8.1303 \text { (3), }\end{array}$

9.6824 (6), 11.3082 (7),

$11.5139(7)$

77.453 (2), 73.445 (2), 87.978

1179.07 (13)

4

1.390

Synchrotron,

$\lambda=0.67510 \AA$

6881

$2.1-28.8$

0.31

Needle, colourless

$0.10 \times 0.02 \times 0.02$

\section{Bruker SMART APEX2 \\ CCD diffractometer}

Fine-slice $\omega$ scans

Multi-scan

0.970

0.994

$12982,6881,5217$

$11.5356(6)$

84.032 (3), 84.297 (2), 69.569

(3)

$593.32(5)$

2

1.504

Mo $K \alpha$

2720

3.3-27.8

0.33

Plate, colourless

$0.18 \times 0.16 \times 0.03$

Bruker-Nonius $95 \mathrm{~mm} \mathrm{CCD}$ camera on $\kappa$ goniostat

$\varphi$ and $\omega$ scans

Multi-scan

0.933

0.990

$12303,2720,1943$

$I>2 \sigma(I)$
0.022
28.8
$-13 \Rightarrow h \Rightarrow 13$
$-16 \Rightarrow k \Rightarrow 16$
$-16 \Rightarrow l \Rightarrow 16$

$I>2 \sigma(I)$

0.052

27.8

$-8 \Rightarrow h \Rightarrow 8$

$-9 \Rightarrow k \Rightarrow 10$

$-14 \Rightarrow l \Rightarrow 14$

$F^{2}$

$0.044,0.124,1.02$

6881

309

Constrained to parent site

$w=1 /\left[\sigma^{2}\left(F_{o}^{2}\right)+(0.0648 P)^{2}+\right.$ $0.3225 P]$, where $P=\left(F_{o}^{2}+\right.$ $\left.2 F_{c}^{2}\right) / 3$

0.001

$0.43,-0.30$

$F^{2}$

$0.044,0.113,1.05$

2720

163

Constrained to parent site

$w=1 /\left[\sigma^{2}\left(F_{o}^{2}\right)+(0.0536 P)^{2}+\right.$ $0.1705 P]$, where $P=\left(F_{o}^{2}+\right.$ $\left.2 F_{c}^{2}\right) / 3$

$<0.0001$

$0.26,-0.29$

$-$

$-$
(IV)

$\mathrm{C}_{12} \mathrm{H}_{8} \mathrm{Cl}_{2} \mathrm{~N}_{2} \mathrm{O}$

267.10

Monoclinic, $P 2_{1}$

$120(2)$

5.0855 (8), $28.982(8)$,

15.607 (4)

90, 90.37 (2), 90

$2300.2(9)$

8

1.543

Mo $K \alpha$

9787

3.0-27.5

0.55

Plate, colourless

$0.28 \times 0.07 \times 0.03$

Bruker-Nonius $95 \mathrm{~mm}$ CCD camera on $\kappa$ goniostat $\varphi$ and $\omega$ scans

Multi-scan

0.862

0.984

$24726,9787,6370$

$I>2 \sigma(I)$

0.053

27.5

$-6 \Rightarrow h \Rightarrow 6$

$-37 \Rightarrow k \Rightarrow 37$

$-20 \Rightarrow l \Rightarrow 20$

$F^{2}$

$0.069,0.169,1.04$

9787

254

Constrained to parent site

$w=1 /\left[\sigma^{2}\left(F_{o}^{2}\right)+(0.0454 P)^{2}+\right.$ 5.774P], where $P=\left(F_{o}^{2}+\right.$ $\left.2 F_{c}^{2}\right) / 3$

0.001

$0.79,-0.54$

Flack (1983), 4396 Friedel pairs

0.54 (11)
(V)

(VI)

(VII)

(VIII)

Crystal data

Chemical formula

$M_{r}$

Cell setting, space group

Temperature (K)

$a, b, c(\AA)$

$\alpha, \beta, \gamma\left(^{\circ}\right)$

$V\left(\AA^{3}\right)$

$Z$
$D_{x}\left(\mathrm{Mg} \mathrm{m}^{-3}\right)$

Radiation type

$\mathrm{C}_{12} \mathrm{H}_{8} \mathrm{BrClN}_{2} \mathrm{O}$
311.56
Orthorhombic, $P 2_{1} 2_{1} 2_{1}$
$120(2)$
$4.8810(2), 13.3448(2)$,
$\quad 18.3974(3)$
$90,90,90$

$1198.33(6)$

4

Mo $K \alpha$

$\mathrm{C}_{12} \mathrm{H}_{8} \mathrm{ClIN}_{2} \mathrm{O}$
358.55
Orthorhombic, Pbca
$120(2)$
$10.6597(2), 25.9833(3)$,
$\quad 9.2044(6)$
$90,90,90$

2549.38 (18)

8

1.868

Mo $K \alpha$

$\mathrm{C}_{13} \mathrm{H}_{11} \mathrm{ClN}_{2} \mathrm{O}_{2}$
262.69
Orthorhombic, $P 2{ }_{1} 2{ }_{1} 2_{1}$
$120(2)$
$4.8536(2), 11.8437(4)$,
$21.0612(7)$
$90,90,90$

1210.69 (6)

4

1.441

Mo $K \alpha$
$\mathrm{C}_{13} \mathrm{H}_{8} \mathrm{ClN}_{3} \mathrm{O}$

257.67

Triclinic, $P \overline{1}$

120 (2)

7.2885 (3), 7.7607 (3), 20.8849 (9)

96.456 (2), 92.913 (2), 91.810

(2)

$1171.49(8)$

4

1.461

Mo $K \alpha$ 
Table 1 (continued)

\begin{tabular}{|c|c|c|c|c|}
\hline & $(\mathrm{V})$ & $(\mathrm{VI})$ & $(\mathrm{VII})$ & (VIII) \\
\hline $\begin{array}{l}\text { No. of reflections for cell } \\
\text { parameters }\end{array}$ & 2736 & 2909 & 2661 & 5365 \\
\hline$\theta$ range $\left(^{\circ}\right)$ & $3.0-27.5$ & $3.0-27.5$ & $3.6-27.5$ & $2.9-27.6$ \\
\hline$\mu\left(\mathrm{mm}^{-1}\right)$ & 3.64 & 2.71 & 0.31 & 0.32 \\
\hline Crystal form, colour & Block, colourless & Plate, colourless & Block, colourless & Block, colourless \\
\hline Crystal size (mm) & $0.16 \times 0.16 \times 0.16$ & $0.33 \times 0.18 \times 0.07$ & $0.34 \times 0.22 \times 0.12$ & $0.40 \times 0.10 \times 0.10$ \\
\hline \multicolumn{5}{|l|}{ Data collection } \\
\hline Diffractometer & $\begin{array}{l}\text { Bruker-Nonius } 95 \mathrm{~mm} \text { CCD } \\
\text { camera on } \kappa \text { goniostat }\end{array}$ & $\begin{array}{l}\text { Bruker-Nonius } 95 \mathrm{~mm} \text { CCD } \\
\text { camera on } \kappa \text { goniostat }\end{array}$ & $\begin{array}{c}\text { Bruker-Nonius } 95 \mathrm{~mm} \text { CCD } \\
\text { camera on } \kappa \text { goniostat }\end{array}$ & $\begin{array}{c}\text { Bruker-Nonius } 95 \mathrm{~mm} \text { CCD } \\
\text { camera on } \kappa \text { goniostat }\end{array}$ \\
\hline Data collection method & $\varphi$ and $\omega$ scans & $\varphi$ and $\omega$ scans & $\varphi$ and $\omega$ scans & $\varphi$ and $\omega$ scans \\
\hline Absorption correction & Multi-scan & Multi-scan & Multi-scan & Multi-scan \\
\hline$T_{\min }$ & 0.558 & 0.469 & 0.921 & 0.899 \\
\hline$T_{\max }$ & 0.558 & 0.833 & 0.964 & 0.969 \\
\hline $\begin{array}{l}\text { No. of measured, indepen- } \\
\text { dent and observed } \\
\text { reflections }\end{array}$ & $36201,2736,2597$ & $19649,2909,2314$ & $7884,2661,2184$ & $21639,5365,3760$ \\
\hline $\begin{array}{l}\text { Criterion for observed } \\
\text { reflections }\end{array}$ & $I>2 \sigma(I)$ & $I>2 \sigma(I)$ & $I>2 \sigma(I)$ & $I>2 \sigma(I)$ \\
\hline$R_{\text {int }}$ & 0.047 & 0.038 & 0.040 & 0.060 \\
\hline$\theta_{\max }\left({ }^{\circ}\right)$ & 27.5 & 27.5 & 27.5 & 27.6 \\
\hline Range of $h, k, l$ & $-6 \Rightarrow h \Rightarrow 6$ & $-13 \Rightarrow h \Rightarrow 13$ & $-5 \Rightarrow h \Rightarrow 6$ & $-9 \Rightarrow h \Rightarrow 9$ \\
\hline & $-17 \Rightarrow k \Rightarrow 17$ & $-32 \Rightarrow k \Rightarrow 33$ & $-15 \Rightarrow k \Rightarrow 11$ & $-10 \Rightarrow k \Rightarrow 10$ \\
\hline & $-23 \Rightarrow l \Rightarrow 23$ & $-11 \Rightarrow l \Rightarrow 11$ & $-21 \Rightarrow l \Rightarrow 27$ & $-27 \Rightarrow l \Rightarrow 26$ \\
\hline \multicolumn{5}{|l|}{ Refinement } \\
\hline Refinement on & $F^{2}$ & $F^{2}$ & $F^{2}$ & $F^{2}$ \\
\hline$R\left[F^{2}>2 \sigma\left(F^{2}\right)\right], w R\left(F^{2}\right), S$ & $0.023,0.060,1.07$ & $0.023,0.056,1.04$ & $0.042,0.104,1.04$ & $0.059,0.171,1.06$ \\
\hline No. of reflections & 2736 & 2909 & 2661 & 5365 \\
\hline No. of parameters & 154 & 154 & 164 & 325 \\
\hline $\mathrm{H}$-atom treatment & Constrained to parent site & Constrained to parent site & Constrained to parent site & Constrained to parent site \\
\hline Weighting scheme & $\begin{array}{l}w=1 /\left[\sigma^{2}\left(F_{o}^{2}\right)+(0.0339 P)^{2}+\right. \\
0.2964 P], \text { where } P=\left(F_{o}^{2}+\right. \\
\left.2 F_{c}^{2}\right) / 3\end{array}$ & $\begin{array}{l}w=1 /\left[\sigma^{2}\left(F_{o}^{2}\right)+(0.026 P)^{2}+\right. \\
0.5926 P], \text { where } P=\left(F_{o}^{2}+\right. \\
\left.2 F_{c}^{2}\right) / 3\end{array}$ & $\begin{array}{c}w=1 /\left[\sigma^{2}\left(F_{o}^{2}\right)+(0.0579 P)^{2}\right] \\
\text { where } P=\left(F_{o}^{2}+2 F_{c}^{2}\right) / 3\end{array}$ & $\begin{array}{l}w=1 /\left[\sigma^{2}\left(F_{o}^{2}\right)+(0.0844 P)^{2}+\right. \\
1.0407 P], \text { where } P=\left(F_{o}^{2}+\right. \\
\left.2 F_{c}^{2}\right) / 3\end{array}$ \\
\hline$(\Delta / \sigma)_{\max }$ & 0.001 & 0.005 & $<0.0001$ & $<0.0001$ \\
\hline$\Delta \rho_{\max }, \Delta \rho_{\min }\left(\mathrm{e} \AA^{-3}\right)$ & $0.43,-0.52$ & $0.39,-0.78$ & $0.24,-0.35$ & $0.74,-0.35$ \\
\hline Absolute structure & $\begin{array}{l}\text { Flack (1983), } 1098 \text { Friedel } \\
\text { pairs }\end{array}$ & - & $\begin{array}{l}\text { Flack (1983), } 1013 \text { Friedel } \\
\text { pairs }\end{array}$ & - \\
\hline Flack parameter & $0.031(7)$ & - & $-0.05(7)$ & - \\
\hline
\end{tabular}

means of the dihedral angle denoted $\Delta$ between the two rings of each molecule, also shown in Table 2. It is striking to note the relationships between the conformations of the four independent molecules in (IV), shown particularly clearly by the dihedral angles $\Delta$ : molecules 1 and 2, containing N21 and N41 respectively, are close to being enantiomorphs, as are molecules 3 and 4 containing N61 and N81. However, the relationships between molecules 1 and 3 , and between molecules 2 and 4 is that of diastereoisomers. The wide range of the dihedral angles $\Delta$ in (I)-(IX), varying from $10.2(2)^{\circ}$ in (VII) to $89.4(2)^{\circ}$ in molecule 2 of (VIII), indicates that the intramolecular barriers to rotation about the $\mathrm{C}-\mathrm{C}$ bonds connecting the rings to the central spacer unit are rather readily overcome by the intermolecular forces, in particular by the direction-specific hydrogen bonds. In this way the observed conformations are an indirect reflection of the action of the hydrogen bonds, just as the detailed supramolecular aggregation patterns are a direct reflection of the action of the hydrogen bonds. The bond lengths and angles present no unusual features.

\subsection{Supramolecular structures}

3.3.1. Compound (I). In the unsubstituted parent compound, (I) (Fig. 1), the molecules are linked into sheets by a combination of $\mathrm{N}-\mathrm{H} \cdots \mathrm{N}, \mathrm{C}-\mathrm{H} \cdots \pi$ (pyridyl) and $\mathrm{C}-$ $\mathrm{H} \cdots \pi$ (arene) hydrogen bonds, but $\mathrm{N}-\mathrm{H} \cdots \mathrm{O}$ hydrogen bonds are absent (Table 3). The formation of the sheets is most conveniently analysed and described in terms of the chains formed by the $\mathrm{N}-\mathrm{H} \cdots \mathrm{N}$ and $\mathrm{C}-\mathrm{H} \cdots \pi$ (pyridyl) hydrogen bonds, and the linkage of the chains by the $\mathrm{C}-\mathrm{H} \cdots \pi$ (arene) hydrogen bonds.

The amidic $\mathrm{N} 21$ atom in the molecule at $(x, y, z)$ acts as a hydrogen-bond donor to the pyridyl N11 atom in the molecule at $\left(\frac{1}{2}-x, y,-\frac{1}{2}+z\right.$ ), thus forming a $C(7)$ (Bernstein et al., 1995) chain running parallel to the [001] direction and generated by the $c$ glide plane at $x=0.25$. This chain is reinforced by the $-\mathrm{H} \cdots \pi$ (pyridyl) hydrogen bond, where the $\mathrm{C} 16$ atom in the molecule at $(x, y, z)$ acts as a donor to the pyridyl ring in the molecule at $\left(\frac{1}{2}-x, y, \frac{1}{2}+z\right)$, thus forming a [001] chain of rings generated by the $c$ glide plane at $y=0.25$ (Fig. 2). 
Table 2

Selected torsional and dihedral angles $\left(^{\circ}\right)$.

\begin{tabular}{|c|c|c|c|}
\hline $\mathrm{C} 13-\mathrm{C} 17-\mathrm{N} 21-\mathrm{C} 21$ & $\mathrm{C} 12-\mathrm{C} 13-\mathrm{C} 17-\mathrm{N} 21$ & $\mathrm{C} 17-\mathrm{N} 21-\mathrm{C} 21-\mathrm{C} 22$ & $\Delta \dagger$ \\
\hline \multicolumn{4}{|l|}{ (I) } \\
\hline $178.8(2)$ & $-56.2(4)$ & $-171.8(2)$ & $48.2(2)$ \\
\hline \multicolumn{4}{|l|}{ (II) } \\
\hline $175.30(13)$ & $-99.53(16)$ & $-141.82(15)$ & $59.8(2)$ \\
\hline $175.77(13) \ddagger$ & $-103.14(16) \dagger$ & $166.05(14) \dagger$ & $62.9(2)$ \\
\hline \multicolumn{4}{|l|}{ (III) } \\
\hline 171.39 (18) & $130.5(2)$ & $174.60(18)$ & $62.6(2)$ \\
\hline \multicolumn{4}{|l|}{ (IV) } \\
\hline $175.0(6)$ & $135.5(8)$ & $149.0(6)$ & $78.2(3)$ \\
\hline$-176.7(6) \ddagger$ & $-137.9(8) \dagger$ & $-148.6(5) \dagger$ & 77.8 (3) \\
\hline $173.9(6) 末$ & $134.4(8) \dagger$ & $-141.9(6) \dagger$ & $12.4(3)$ \\
\hline$-176.9(6)$ 丰 & $-138.0(8) \dagger$ & $144.9(5) \dagger$ & $11.5(3)$ \\
\hline \multicolumn{4}{|l|}{ (V) } \\
\hline $178.86(17)$ & $51.3(3)$ & $143.6(2)$ & $17.2(2)$ \\
\hline \multicolumn{4}{|l|}{ (VI) } \\
\hline 172.75 (19) & $-77.3(2)$ & $-135.9(2)$ & $35.4(2)$ \\
\hline \multicolumn{4}{|l|}{ (VII) } \\
\hline$-179.41(18)$ & $-134.5(2)$ & $141.0(2)$ & $10.2(2)$ \\
\hline \multicolumn{4}{|l|}{ (VIII) } \\
\hline $170.3(3)$ & $-73.7(4)$ & $-163.6(3)$ & $60.9(2)$ \\
\hline$-174.2(3) \ddagger$ & $90.9(3) \dagger$ & $177.8(3) \dagger$ & $89.4(3)$ \\
\hline \multicolumn{4}{|l|}{$(\mathrm{IX}) \S$} \\
\hline 173.29 (19) & $78.1(3)$ & $-179.8(2)$ & $73.3(2)$ \\
\hline$-173.4(2) \ddagger$ & $-71.5(3) \dagger$ & $173.6(2) \dagger$ & $73.6(3)$ \\
\hline
\end{tabular}

$\dagger \Delta$ is the dihedral angle between the two rings in each independent molecule. $\ddagger$ In molecule 2 of (II), (IV), (VIII) and (IX) the relevant atom sequence is $\mathrm{C} 32-\mathrm{C} 33-\mathrm{C} 37-\mathrm{N} 41-\mathrm{C} 41-\mathrm{C} 42$; in molecules 3 and 4 of (IV) the relevant atom sequences are C52-C53-C57-N61-C61-C62 and C72-C73-C77-N81-C81-C82, respectively (see Figs. 5, 12 and 25). $§$ Data from de Souza et al. (2005).

Four chains of this type pass though each unit cell, two each in the domains $0.25<y<0.75$ and $-0.25<y<0.25$, and within each domain, one chain is generated by the $c$ glide plane at 0.25 , and the other, antiparallel to the first, is generated by the $c$ glide plane at $y=0.75$. A simple centrosymmetric motif serves to link the antiparallel pairs of [001] chains in each domain to form sheets. The $\mathrm{C} 15$ atom in the molecule at $(x, y, z)$, which is part of a chain generated by the glide plane at $x=0.25$, acts as a hydrogen-bond donor to the phenyl ring in the molecule at $(1-x, 1-y, 1-z)$, which is part of a chain generated by the glide plane at $x=0.75$ (Fig. 3). Propagation of this interaction then links all the chains in a given domain of $y$ into a (010) sheet (Fig. 4): two sheets, related to one another by the twofold rotation axes parallel to [001], pass through each unit cell, but there are no direction-specific interactions between adjacent sheets.

3.3.2. Compound (II). In the 4-methylphenyl derivative (II), where $Z^{\prime}=2$ (Fig. 5), the molecules are linked by two independent $\mathrm{N}-\mathrm{H} \cdots \mathrm{O}$ hydrogen bonds (Table 3 ) into $C_{2}^{2}(8)$ chains (Fig. 6): it is convenient to refer to molecules containing atoms $\mathrm{O} 1$ and $\mathrm{O} 3$ as 1 and 2, respectively. Two antiparallel $C_{2}^{2}(8)$ chains pass through each unit cell and these chains are linked into a chain of edge-fused rings by a single, nearly linear $\mathrm{C}-\mathrm{H} \cdots \mathrm{O}$ hydrogen bond, where the pyridyl $\mathrm{C} 35$ atom in molecule 2 at $(x, y, z)$ acts as a hydrogen-bond donor to the $\mathrm{O} 1$ atom in molecule 1 at $(1-x, 1-y, 1-z)$. Propagation by translation and inversion of these three hydrogen bonds, two of the $\mathrm{N}-\mathrm{H} \cdots \mathrm{O}$ type and one of the $\mathrm{C}-\mathrm{H} \cdots \mathrm{O}$ type, generates a chain of centrosymmetric, edge-fused rings along $\left(x, \frac{1}{2}, \frac{1}{2}\right)$, with $R_{4}^{2}(16)$ rings centred at $\left(n, \frac{1}{2}, \frac{1}{2}\right) \quad(n=$ zero or integer $)$ and $R_{4}^{4}(20)$ rings centred at $\left(n+\frac{1}{2}, \frac{1}{2}, \frac{1}{2}\right)(n=$ zero or integer; Fig. 7$)$.

There are two $\mathrm{C}-\mathrm{H} \cdots \pi$ (arene) hydrogen bonds in the structure of (II) (Table 3): one, having the C34 atom as the donor, lies within the [100] chain of rings, but the other, having $\mathrm{C} 14$ as the donor, links the [100] chains into sheets. The C14 atom in molecule 1 at $(x, y, z)$ lies in the chain along $\left(x, \frac{1}{2}, \frac{1}{2}\right)$ : this atom acts as a donor to the phenyl ring C41-C46 in molecule 2 at $(1-x, 2-y,-z)$, which lies in the chain along $\left(x, \frac{3}{2},-\frac{1}{2}\right)$. Propagation by inversion of this $\mathrm{C}-\mathrm{H} \cdots \pi$ (arene) hydrogen bond then links [100] chains into a (011) sheet (Fig. 8). There are no direction-specific interactions between adjacent sheets.

3.3.3. Compound (III). The 4-fluorophenyl derivative crystallizes as a monohydrate, compound (III), and in the selected asymmetric unit (Fig. 9) the two components are linked by an $\mathrm{N}-\mathrm{H} \cdots \mathrm{O}$ hydrogen bond: this utilization of the $\mathrm{N}-\mathrm{H}$ donor site immediately precludes the formation of the characteristic amidic $C(4)$ chain. Instead the molecules are linked into chains of edge-fused rings by a combination of $\mathrm{O}-\mathrm{H} \cdots \mathrm{O}$ and $\mathrm{O}-\mathrm{H} \cdots \mathrm{N}$ hydrogen bonds (Table 3 ), and these chains are linked into sheets by a single aromatic $\pi \cdots \pi$ stacking interaction.

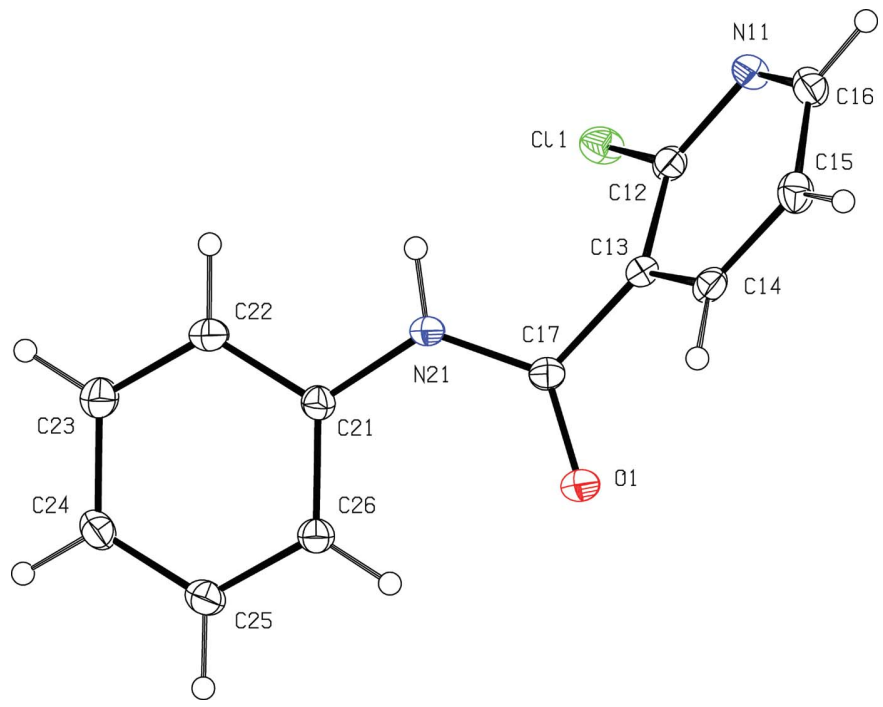

Figure 1

The molecule of (I) showing the atom-labelling scheme. Displacement ellipsoids are drawn at the $30 \%$ probability level. 
The water atom $\mathrm{O} 2$ at $(x, y, z)$ acts as a hydrogen-bond donor, via $\mathrm{H} 2 B$, to the amidic atom $\mathrm{O} 1$ at $(-1+x, y, z)$, thus generating by translation a $C_{2}^{2}(6)$ chain running parallel to the

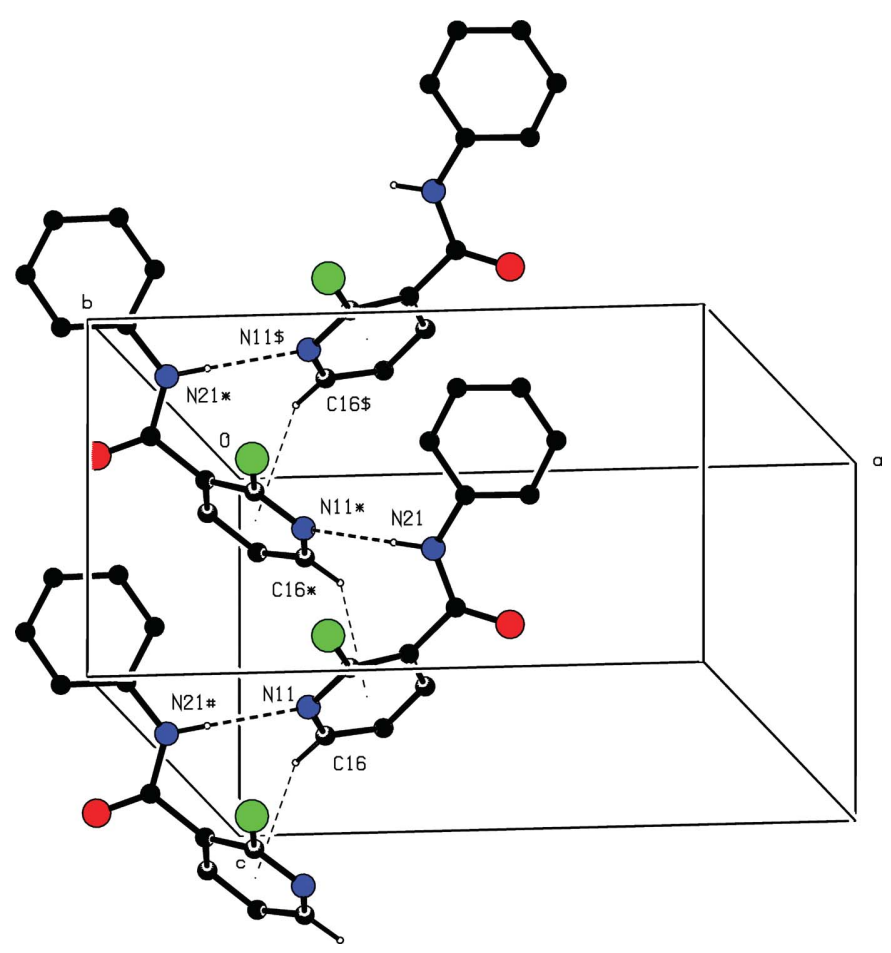

Figure 2

Part of the crystal structure of (I) showing the formation of a hydrogenbonded chain of rings along [001]. For the sake of clarity, the $\mathrm{H}$ atoms not involved in the motifs shown have been omitted. The atoms marked with an asterisk (*), a hash (\#) or a dollar sign (\$) are at the symmetry positions $\left(\frac{1}{2}-x, y-\frac{1}{2}+z\right),\left(\frac{1}{2}-x, y, \frac{1}{2}+z\right)$ and $(x, y,-1+z)$, respectively.

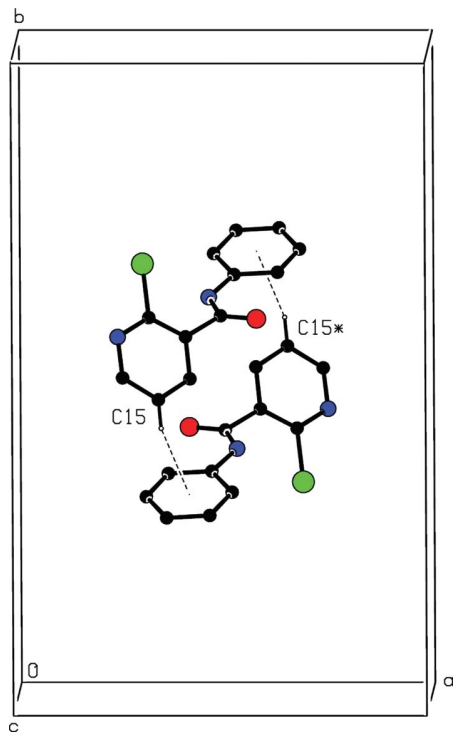

Figure 3

Part of the crystal structure of (I) showing the centrosymmetric ring built from $\mathrm{C}-\mathrm{H} \cdots \pi$ (arene) hydrogen bonds, which link the [001] chains into (010) sheets. For the sake of clarity, the $\mathrm{H}$ atoms not involved in the motif shown have been omitted. The atom marked with an asterisk $(*)$ is at the symmetry position $(1-x, 1-y, 1-z)$.
Table 3

Hydrogen-bond parameters $\left(\AA,^{\circ}\right)$.

\begin{tabular}{|c|c|c|c|}
\hline$D-\mathrm{H} \cdots A$ & $\mathrm{H} \cdots A$ & $D \cdots A$ & $D-\mathrm{H} \cdots A$ \\
\hline \multicolumn{4}{|l|}{ (I) } \\
\hline $\mathrm{N} 21-\mathrm{H} 21 \cdots \mathrm{N} 11^{\mathrm{i}}$ & 2.25 & $3.101(3)$ & 164 \\
\hline $\mathrm{C} 15-\mathrm{H} 15 \cdots \mathrm{Cg} 1^{\mathrm{ii} \dagger}$ & 2.89 & $3.535(3)$ & 126 \\
\hline $\mathrm{C} 16-\mathrm{H} 16 \cdots \mathrm{Cg} 2^{\mathrm{iii}}+$ & 2.87 & $3.464(3)$ & 121 \\
\hline \multicolumn{4}{|l|}{ (II) } \\
\hline $\mathrm{N} 21-\mathrm{H} 21 \cdots \mathrm{O} 3$ & 1.96 & $2.827(2)$ & 170 \\
\hline $\mathrm{N} 41-\mathrm{H} 41 \cdots \mathrm{O} 1^{\mathrm{iv}}$ & 1.99 & $2.847(2)$ & 163 \\
\hline $\mathrm{C} 35-\mathrm{H} 35 \cdots \mathrm{O} 1^{\mathrm{ii}}$ & 2.48 & $3.424(2)$ & 174 \\
\hline $\mathrm{C} 14-\mathrm{H} 14 \cdots \mathrm{Cg} 3^{\mathrm{v}} \S$ & 2.69 & $3.398(2)$ & 132 \\
\hline $\mathrm{C} 34-\mathrm{H} 34 \cdots \mathrm{Cg}{ }^{\mathrm{ii}_{\ddagger}}$ & 2.63 & $3.398(2)$ & 138 \\
\hline \multicolumn{4}{|l|}{ (III) } \\
\hline $\mathrm{N} 21-\mathrm{H} 21 \cdots \mathrm{O} 2$ & 1.91 & $2.837(2)$ & 179 \\
\hline $\mathrm{O} 2-\mathrm{H} 2 A \cdots \mathrm{N} 11^{\mathrm{vi}}$ & 1.97 & $2.887(2)$ & 161 \\
\hline $\mathrm{O} 2-\mathrm{H} 2 B \cdots \mathrm{O} 1^{\mathrm{iv}}$ & 1.95 & $2.780(2)$ & 173 \\
\hline \multicolumn{4}{|l|}{ (IV) } \\
\hline $\mathrm{N} 21-\mathrm{H} 21 \cdots \mathrm{O} 1^{\mathrm{iv}}$ & 2.11 & $2.925(8)$ & 153 \\
\hline $\mathrm{N} 41-\mathrm{H} 41 \cdots \mathrm{O}^{\text {iv }}$ & 2.00 & $2.833(8)$ & 157 \\
\hline $\mathrm{N} 61-\mathrm{H} 61 \cdots \mathrm{O} 5^{\mathrm{vii}}$ & 2.11 & $2.925(8)$ & 153 \\
\hline $\mathrm{N} 81-\mathrm{H} 81 \cdots \mathrm{O} 7^{\mathrm{vii}}$ & 2.00 & $2.841(8)$ & 159 \\
\hline $\mathrm{C} 26-\mathrm{H} 26 \cdots \mathrm{Cg} 59$ & 2.76 & $3.444(8)$ & 130 \\
\hline $\mathrm{C} 46-\mathrm{H} 46 \cdots \mathrm{Cg} 4 \dagger \dagger$ & 2.75 & $3.448(8)$ & 131 \\
\hline $\mathrm{C} 62-\mathrm{H} 62 \cdots \mathrm{Cg} 3^{\text {vii }} \S$ & 2.88 & $3.588(8)$ & 132 \\
\hline $\mathrm{C} 82-\mathrm{H} 82 \cdots \mathrm{Cg} 2^{\mathrm{vii}_{+}}$ & 2.87 & $3.579(8)$ & 132 \\
\hline \multicolumn{4}{|l|}{$(\mathrm{V})$} \\
\hline $\mathrm{N} 21-\mathrm{H} 21 \cdots \mathrm{O} 1^{\text {iv }}$ & 2.03 & $2.825(2)$ & 169 \\
\hline $\mathrm{C} 22-\mathrm{H} 22 \cdots \mathrm{N} 11^{\mathrm{viii}}$ & 2.56 & $3.405(3)$ & 148 \\
\hline \multicolumn{4}{|l|}{ (VI) } \\
\hline $\mathrm{N} 21-\mathrm{H} 21 \cdots \mathrm{O} 1^{\mathrm{ix}}$ & 2.01 & $2.853(2)$ & 160 \\
\hline $\mathrm{C} 15-\mathrm{H} 15 \cdots \mathrm{Cg}{ }^{\mathrm{x}} \ddagger$ & 2.65 & $3.404(2)$ & 137 \\
\hline \multicolumn{4}{|l|}{ (VII) } \\
\hline $\mathrm{N} 21-\mathrm{H} 21 \cdots \mathrm{O} 1^{\mathrm{ii}}$ & 1.92 & $2.785(2)$ & 168 \\
\hline \multicolumn{4}{|l|}{ (VIII) } \\
\hline $\mathrm{N} 21-\mathrm{H} 21 \cdots \mathrm{N} 44$ & 2.15 & $3.006(4)$ & 164 \\
\hline $\mathrm{N} 41-\mathrm{H} 41 \cdots \mathrm{N} 24^{\mathrm{xi}}$ & 2.10 & $2.978(4)$ & 173 \\
\hline $\mathrm{C} 14-\mathrm{H} 14 \cdots \mathrm{O} 11^{\mathrm{xii}}$ & 2.49 & $3.334(4)$ & 148 \\
\hline $\mathrm{C} 15-\mathrm{H} 15 \cdots \mathrm{O} 11^{\mathrm{ii}}$ & 2.60 & $3.507(4)$ & 160 \\
\hline $\mathrm{C} 25-\mathrm{H} 25 \cdots \mathrm{N} 11^{\mathrm{xiii}}$ & 2.52 & $3.348(4)$ & 146 \\
\hline $\mathrm{C} 34-\mathrm{H} 34 \cdots \mathrm{O} 31^{\mathrm{xiv}}$ & 2.53 & $3.327(4)$ & 142 \\
\hline $\mathrm{C} 35-\mathrm{H} 35 \cdots \mathrm{O} 31^{\mathrm{ii}}$ & 2.45 & $3.366(4)$ & 161 \\
\hline $\mathrm{C} 45-\mathrm{H} 45 \cdots \mathrm{N} 31^{\mathrm{xiii}}$ & 2.53 & $3.300(4)$ & 138 \\
\hline
\end{tabular}

Symmetry codes: (i) $\frac{1}{2}-x, y,-\frac{1}{2}+z$; (ii) $1-x, 1-y, 1-z$; (iii) $\frac{1}{2}-x, y, \frac{1}{2}+z$; (iv) $-1+x, y, z ;$ (v) $1-x, 2-y,-z$; (vi) $1-x, 2-y, 1-z$; (vii) $1+x, y, z$; (viii) $-x, \frac{1}{2}+y, \frac{1}{2}-z$; (ix) $x, \frac{1}{2}-y, \frac{1}{2}+z$; (x) $-\frac{1}{2}+x, \frac{1}{2}-y, 1-z$; (xi) $-2+x, 1+y, z$; (xii) $1-x,-y, 1-z$; (xiii) $1+x,-1+y, z$; (xiv) $-1-x, 1-y,-z$. $\dagger \mathrm{Cg} 1$ is the centroid of ring N11, C12-C16. $\ddagger \mathrm{Cg} 2$ is the centroid of ring C21-C26. \& $\mathrm{Cg} 3$ is the centroid of ring $\mathrm{C} 41-\mathrm{C} 46 . \quad-\mathrm{Cg} 5$ is the centroid of ring $\mathrm{C} 81-\mathrm{C} 86 . \quad \dagger \dagger \mathrm{Cg} 4$ is the centroid of ring C61-C66.

[100] direction. An antiparallel pair of these $C_{2}^{2}(6)$ chains is linked by the $\mathrm{N}-\mathrm{H} \cdots \mathrm{O}$ hydrogen bond: the $\mathrm{O} 2$ atom at $(x, y, z)$ acts as a donor, via $\mathrm{H} 2 A$, to the pyridyl $\mathrm{N} 11$ atom at $(1-x, 2-y, 1-z)$, thus generating a centrosymmetric $R_{4}^{4}(16)$ ring, centred at $\left(\frac{1}{2}, 1, \frac{1}{2}\right)$. The combination of all the hydrogen bonds then generates, by translation and inversion, a chain of edge-fused $R_{4}^{4}(16)$ rings along $\left(x, 1, \frac{1}{2}\right)$ (Fig. 10). There are two types of ring within this chain and both are centrosymmetric: those having amidic $\mathrm{O}$ atoms as two of the acceptor sites are centred at $\left(n, 1, \frac{1}{2}\right)(n=$ zero or integer $)$, and 
those having water $\mathrm{O}$ atoms as two of the acceptor sites are centred at $\left(n+\frac{1}{2}, 1, \frac{1}{2}\right)(n=$ zero or integer $)$.

The pyridyl rings in the amide molecules at $(x, y, z)$ and $(1-x, 1-y, 2-z)$ are strictly parallel with an interplanar spacing of $3.352(2) \AA$; the ring-centroid separation is 3.618 (2) $\AA$, corresponding to a nearly ideal ring offset of 1.362 (2) $\AA$. These two amide molecules form parts of the chains of fused rings along $\left(x, 1, \frac{1}{2}\right)$ and $\left(x, 0, \frac{3}{2}\right)$, so that propagation by inversion of this stacking interaction forms a
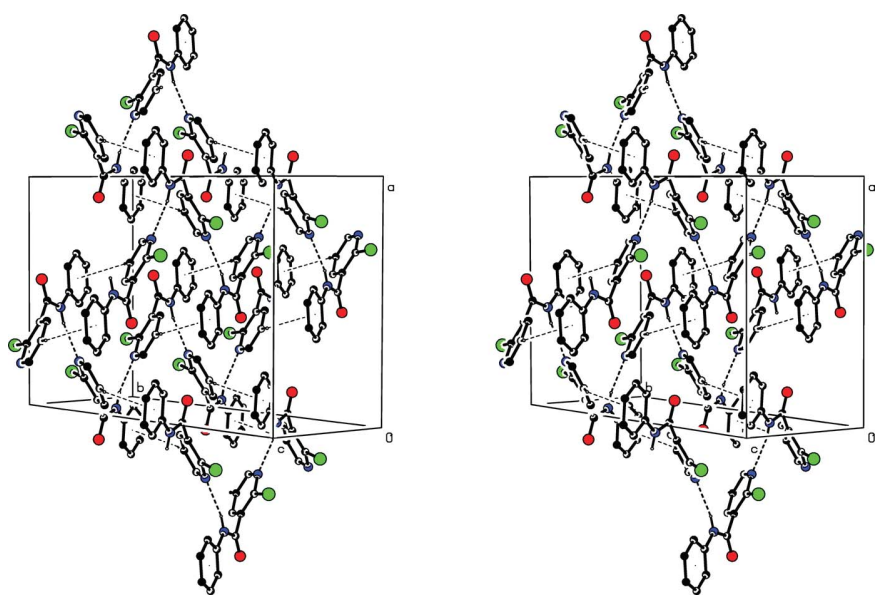

Figure 4

Stereoview of part of the crystal structure of (I), showing a hydrogenbonded (010) sheet. For the sake of clarity, the $\mathrm{H}$ atoms not involved in the motifs shown have been omitted.

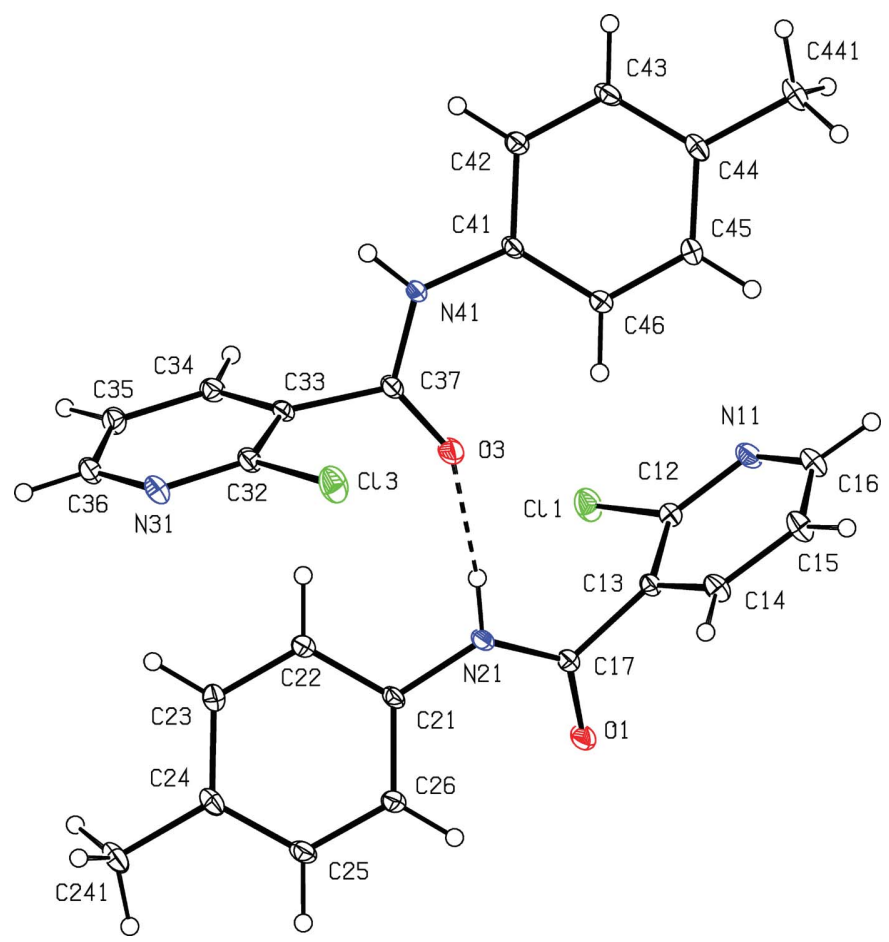

Figure 5

The two independent molecules of (II) showing the atom-labelling scheme and the $\mathrm{N}-\mathrm{H} \cdots \mathrm{O}$ hydrogen bond within the asymmetric unit. Displacement ellipsoids are drawn at the $30 \%$ probability level.
[011] chain (Fig. 11), which links the chains of rings into a (011) sheet.

3.3.4. Compound (IV). We comment here only briefly on the supramolecular aggregation of the 4-chlorophenyl compound (IV). This compound crystallizes in the noncentrosymmetric space group $P 2_{1}$ with $Z^{\prime}=4$ (Fig. 12), but the crystal quality was extremely poor, with extensive twinning. Nonetheless, the main features of the structure are clear enough: each of the four independent molecules forms a $C(4)$ chain by translation along [100], built from $\mathrm{N}-\mathrm{H} \cdots \mathrm{O}$ hydrogen bonds (Fig. 13), and these chains are linked in pairs by the $\mathrm{C}-\mathrm{H} \cdots \pi$ (arene) hydrogen bonds (Table 3 ).

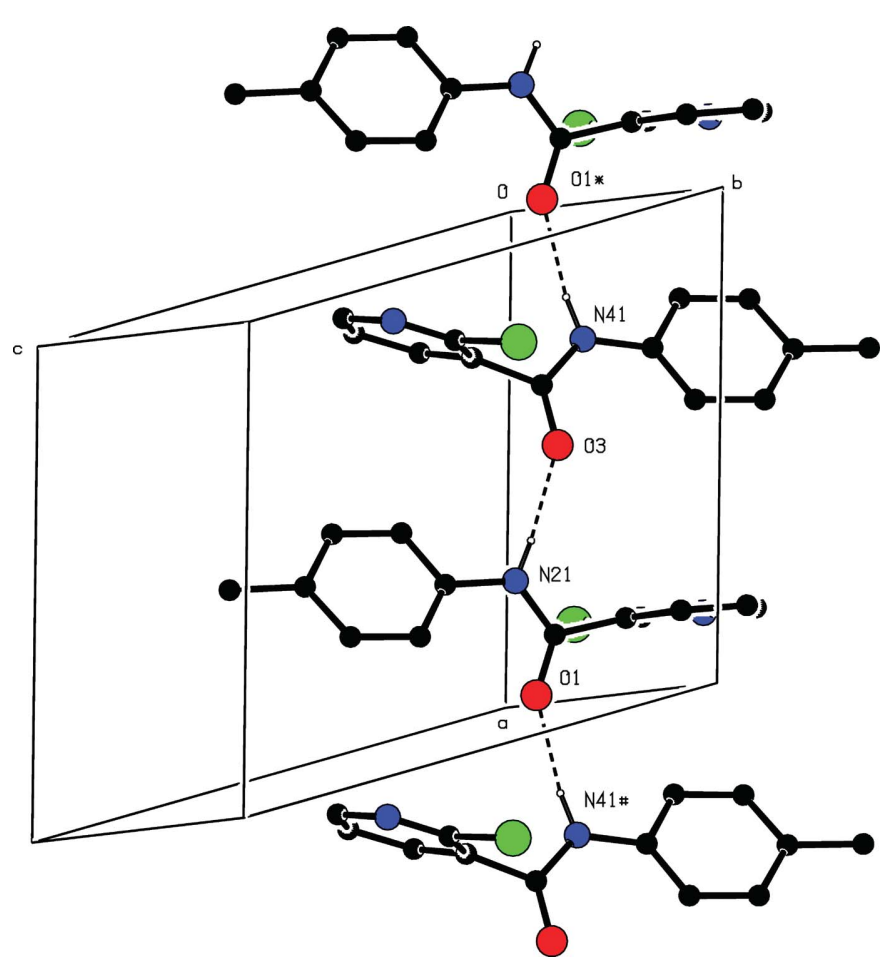

Figure 6

Part of the crystal structure of (II), showing the formation of a $C_{2}^{2}(8)$ chain along [100]. For the sake of clarity, the $\mathrm{H}$ atoms bonded to $\mathrm{C}$ atoms have been omitted. The atoms marked with an asterisk $(*)$ or a hash (\#) are at the symmetry positions $(-1+x, y, z)$ and $(1+x, y, z)$, respectively.
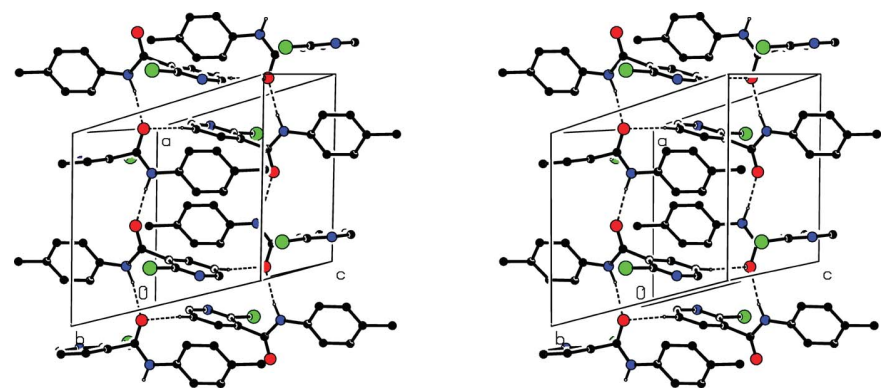

Figure 7

Stereoview of part of the crystal structure of (II) showing the formation of a chain of edge fused $R_{4}^{2}(16)$ and $R_{4}^{4}(20)$ rings along [100]. For the sake of clarity, the $\mathrm{H}$ atoms not involved in the motifs shown have been omitted. 
3.3.5. Compound (V). In the 4-bromophenyl compound (V) (Fig. 14), the molecules are linked into isolated sheets by a combination of one $\mathrm{N}-\mathrm{H} \cdots \mathrm{O}$ and one $\mathrm{C}-\mathrm{H} \cdots \mathrm{N}$ hydrogen bond (Table 3). The amidic N21 atom in the molecule at $(x, y, z)$ acts as a hydrogen-bond donor to the amidic $\mathrm{O} 1$ in the molecule at $(-1+x, y, z)$, so generating by translation a $C(4)$ chain running parallel to the [100] direction (Fig. 15). Four chains of this type pass through each unit cell, two in each of the domains $0<z<0.5$ and $0.5<z<1.0$, and within each of these domains the chains are linked into sheets by a single $\mathrm{C}-$ $\mathrm{H} \cdots \mathrm{N}$ hydrogen bond. The aryl $\mathrm{C} 22$ atom in the molecule at $(x, y, z)$ acts as a hydrogen-bond donor to the pyridyl N11 atom in the molecule at $\left(-x, \frac{1}{2}+y, \frac{1}{2}-z\right)$, so forming a $C(8)$ chain running parallel to the [010] direction, and generated by
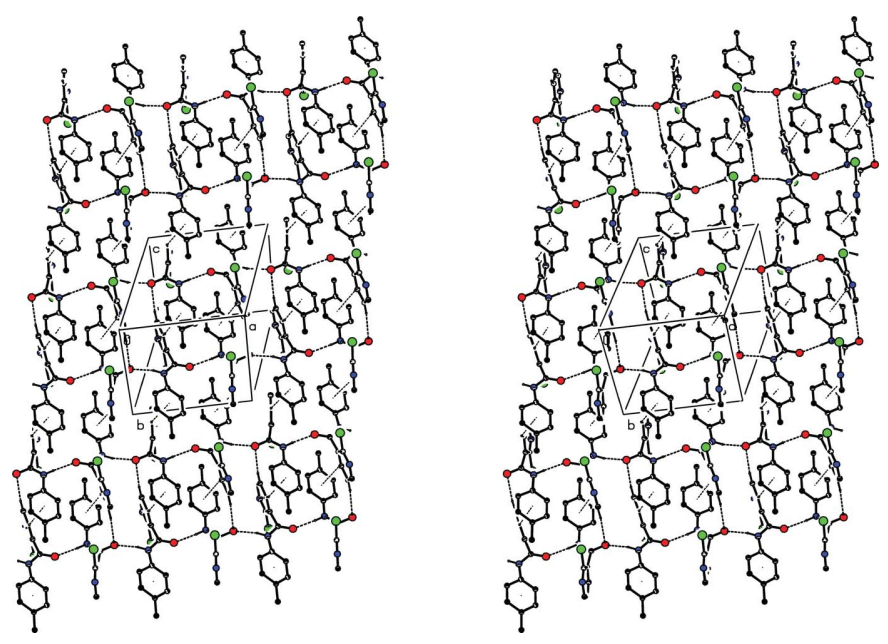

Figure 8

Stereoview of part of the crystal structure of (II) showing the linking, by means of a single $\mathrm{C}-\mathrm{H} \cdots \pi$ (arene) hydrogen bond, of the [100] chains of rings into a (011) sheet. For the sake of clarity, the $\mathrm{H}$ atoms not involved in the motifs shown have been omitted.

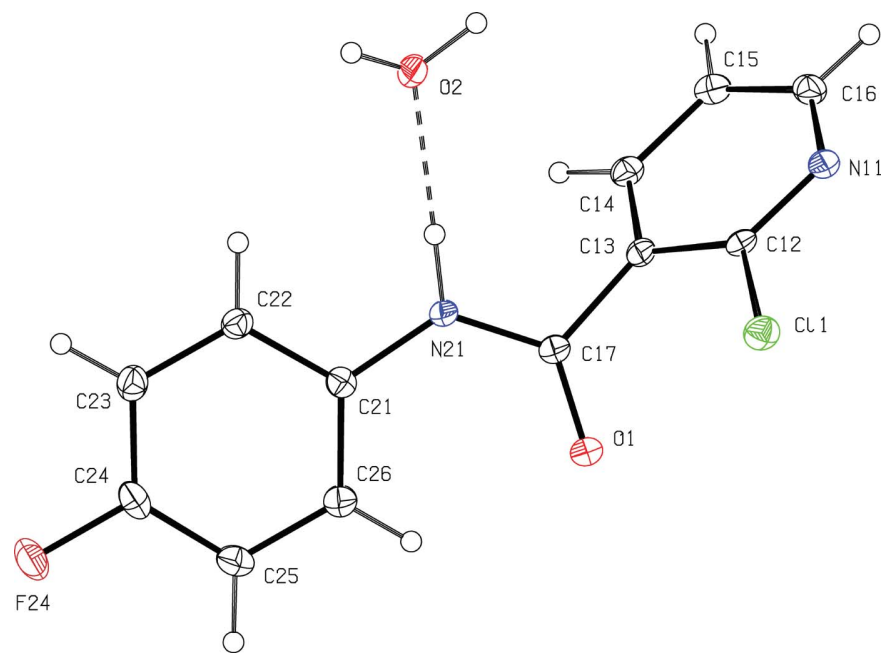

Figure 9

The molecular components of (III) showing the atom-labelling scheme. Displacement ellipsoids are drawn at the $30 \%$ probability level. the $2_{1}$ screw axis along $\left(0, y, \frac{1}{4}\right)$ (Fig. 16). The combination of the [100] and [010] chains then generates a (001) sheet in the form of a $(4,4)$ net built from a single type of $R_{4}^{4}(22)$ ring (Fig.

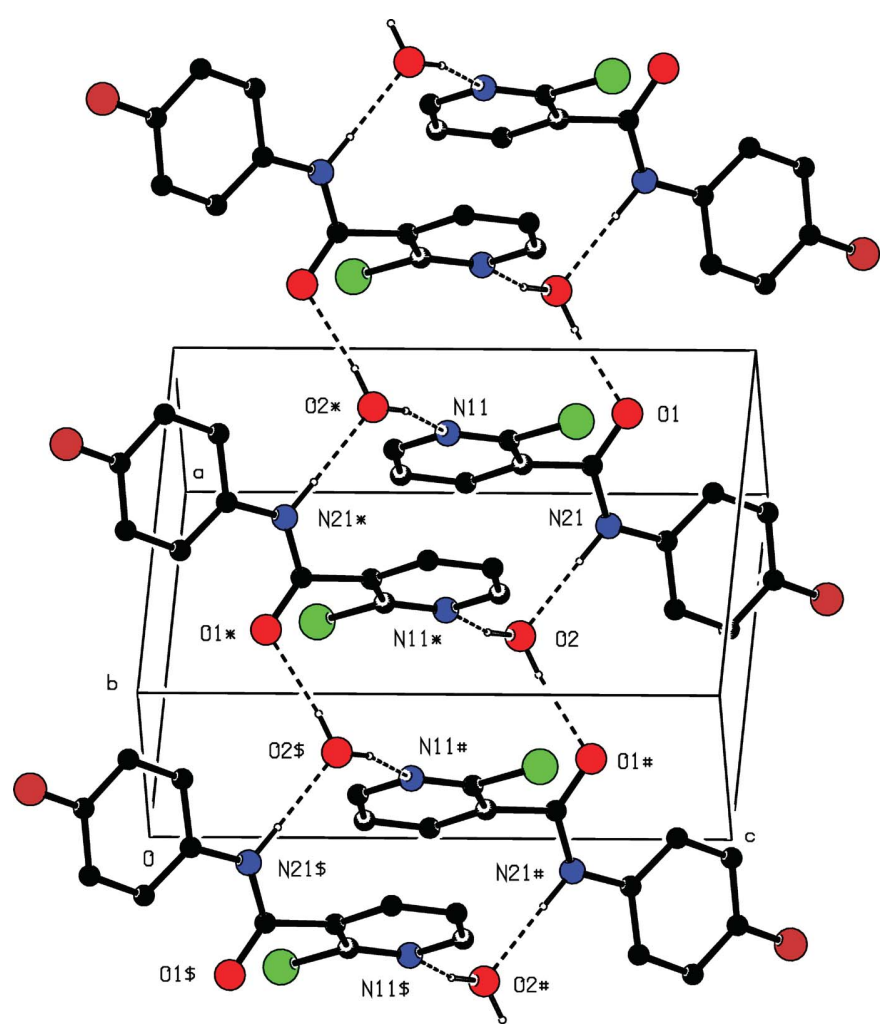

Figure 10

Part of the crystal structure of (III) showing the formation of a hydrogenbonded chain of edge-fused rings along [100]. For the sake of clarity, the $\mathrm{H}$ atoms bonded to $\mathrm{C}$ atoms have been omitted. The atoms marked with an asterisk (*), a hash (\#) or a dollar sign (\$) are at the symmetry positions $(1-x, 2-y, 1-z),(-1+x, y, z)$ and $(-x, 2-y, 1-z)$, respectively.
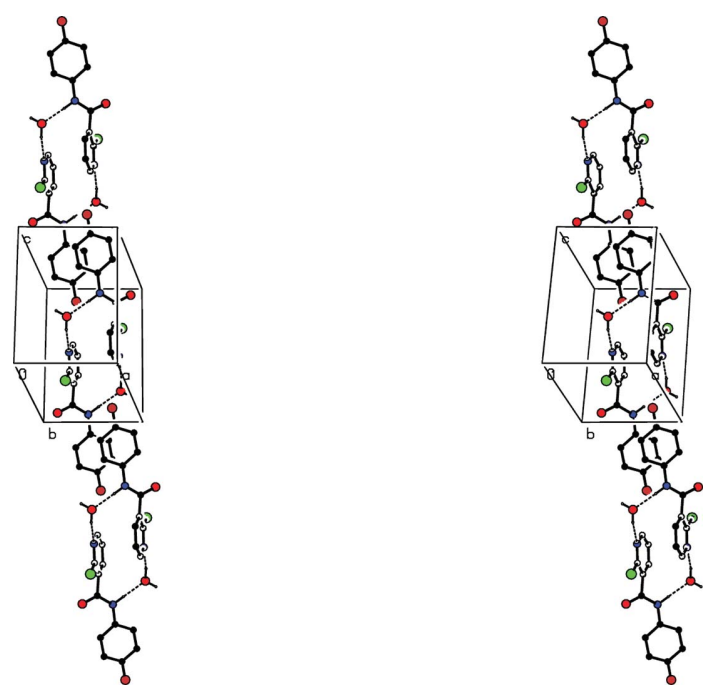

Figure 11

Stereoview of part of the crystal structure of (III) showing the centrosymmetric $\pi$-stacking interaction which links the [100] chains into (011) sheets. For the sake of clarity, the $\mathrm{H}$ atoms bonded to $\mathrm{C}$ atoms have been omitted. 


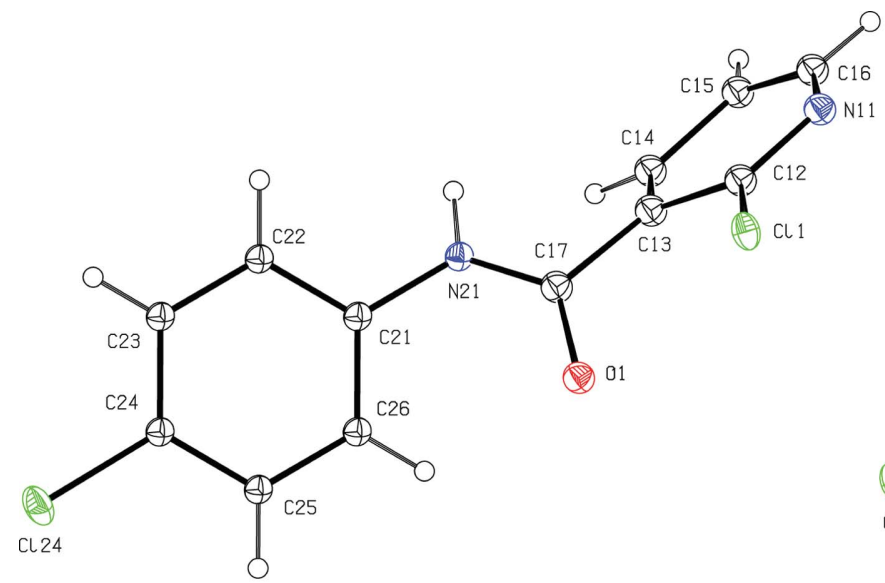

(a)

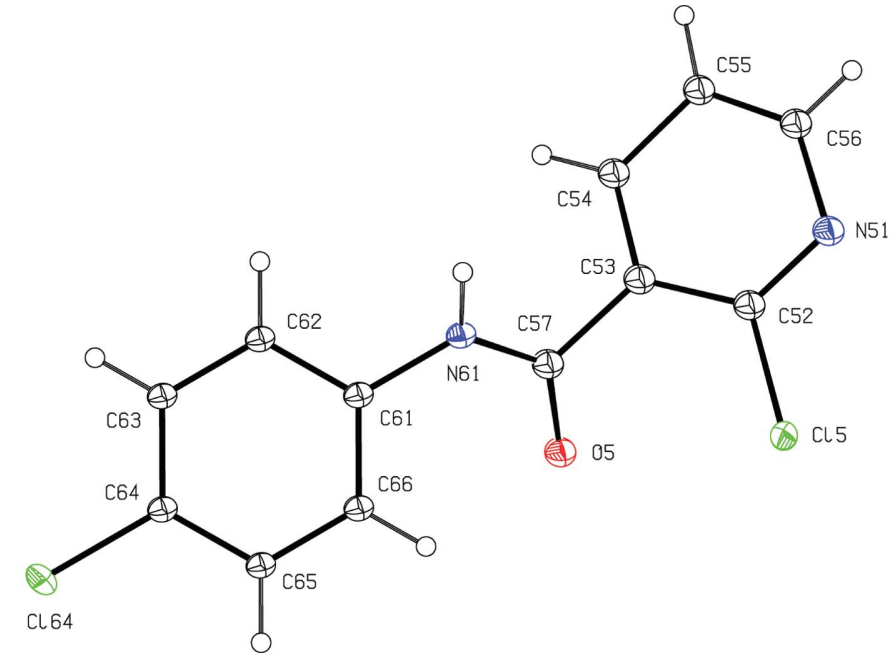

(c)

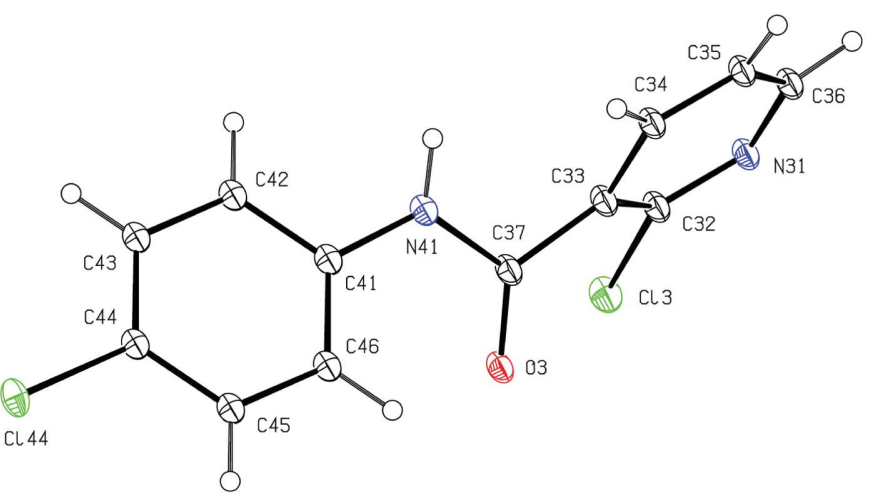

(b)

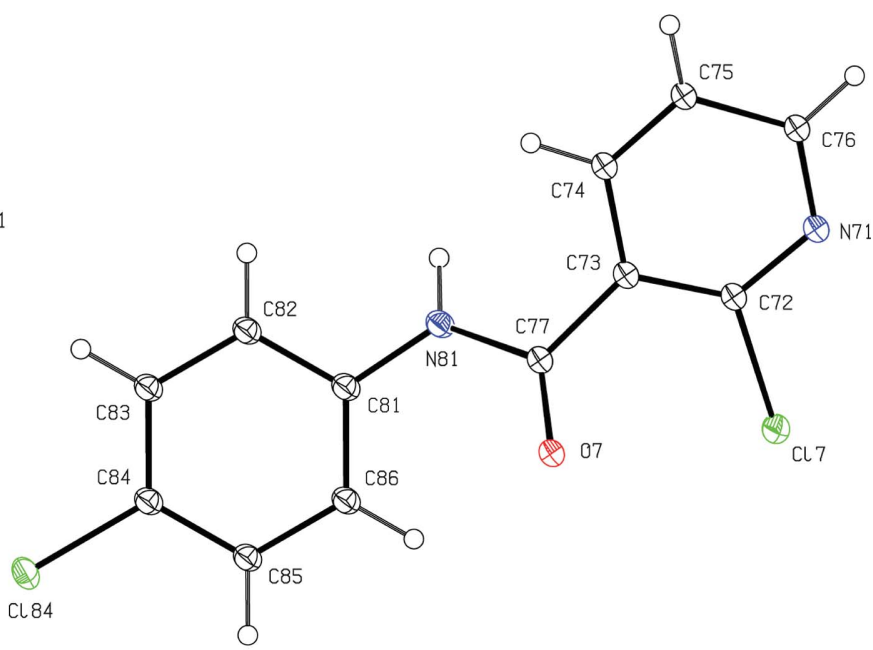

$(d)$

Figure 12

The four independent molecules of (IV) showing the atom-labelling scheme. Displacement ellipsoids are drawn at the $30 \%$ probability level. The atom labelling for the other three molecules and the conformational differences between the molecules are defined in Table 2 .

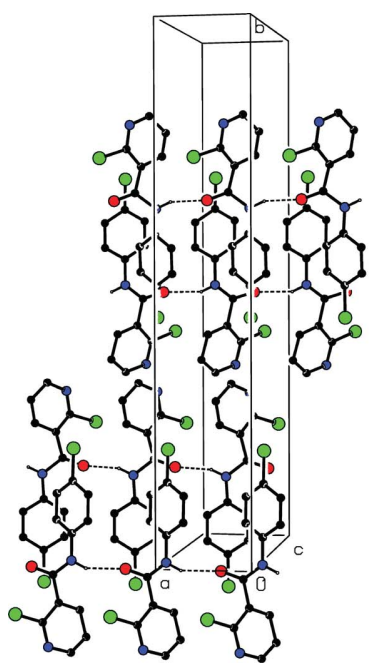

Figure 13

Stereoview of part of the crystal structure of (IV) showing the formation of four independent $C(4)$ chains along [100]. For the sake of clarity, the $\mathrm{H}$ atoms bonded to $\mathrm{C}$ atoms have been omitted.

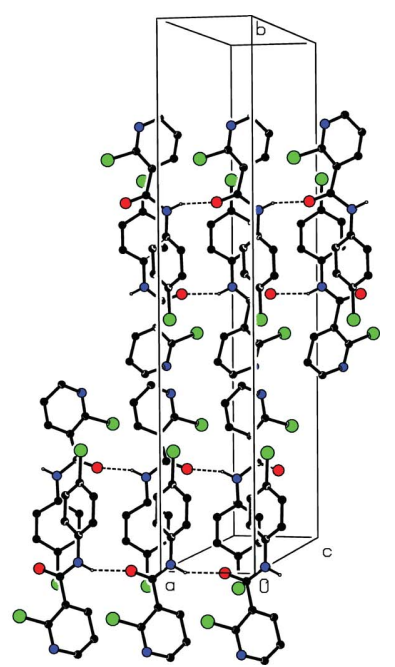

17). Two sheets of this type pass through each unit cell, generated by screw axes at $y=0.25$ and $y=0.75$, respectively, but there are no direction-specific interactions between adjacent sheets: in particular, aromatic $\pi \cdots \pi$ stacking interactions and $\mathrm{C}-\mathrm{H} \cdots \pi$ (arene) hydrogen bonds are absent.

3.3.6. Compound (VI). The molecules of the 4-iodophenyl compound (VI) (Fig. 18) are linked into sheets by a combination of one $\mathrm{N}-\mathrm{H} \cdots \mathrm{O}$ hydrogen bond and one $\mathrm{C}-$ $\mathrm{H} \cdots \pi$ (arene) hydrogen bond (Table 3 ) and these sheets are themselves linked by a single iodo $\cdots \mathrm{N}$ (pyridyl) interaction. The $\mathrm{N} 21$ atom in the molecule at $(x, y, z)$ acts as a hydrogenbond donor to the $\mathrm{O} 1$ atom in the molecule at $\left(x, \frac{1}{2}-y, \frac{1}{2}+z\right)$, so forming a $C(4)$ chain running parallel to the [001] direction, and generated by the $c$-glide plane at $y=0.25$ (Fig. 19). In addition, the pyridyl $\mathrm{C} 15$ atom in the molecule at $(x, y, z)$ acts as a hydrogen-bond donor to the aryl ring $\mathrm{C} 21-\mathrm{C} 26$ in the molecule at $\left(-\frac{1}{2}+x, \frac{1}{2}-y, 1-z\right)$, so forming a chain running parallel to the [100] direction and generated by the $2_{1}$ screw axis along $\left(x, \frac{1}{4}, \frac{1}{2}\right)$ (Fig. 20). The combination of these two 
hydrogen-bonded motifs then generates a (010) sheet (Fig. 21): two sheets of this type pass through each unit cell, in the domains $-0.02<y<0.52$ and $0.48<y<1.02$. The sole direction-specific interaction between adjacent sheets is an iodo...N(pyridyl) interaction, somewhat analogous electronically to an iodo - nitro interaction: the I24 atom in the molecule at $(x, y, z)$ forms a short contact with the pyridyl N11 atom in the molecule at $\left(\frac{3}{2}-x, \frac{1}{2}+y, z\right)$, with dimensions $\mathrm{I} \cdots \mathrm{N}^{\mathrm{i}} 3.116(2) \AA, \mathrm{C}-\mathrm{I} \cdots \mathrm{N}^{\mathrm{i}} 167.5(2)^{\circ}$ [symmetry code (i) $\left.\frac{3}{2}-x, \frac{1}{2}+y, z\right]$. This interaction thus forms a $C(10)$ chain (Starbuck et al., 1999) running parallel to the [010] direction and generated by a $b$-glide plane at $y=0.75$ (Fig. 22): in this

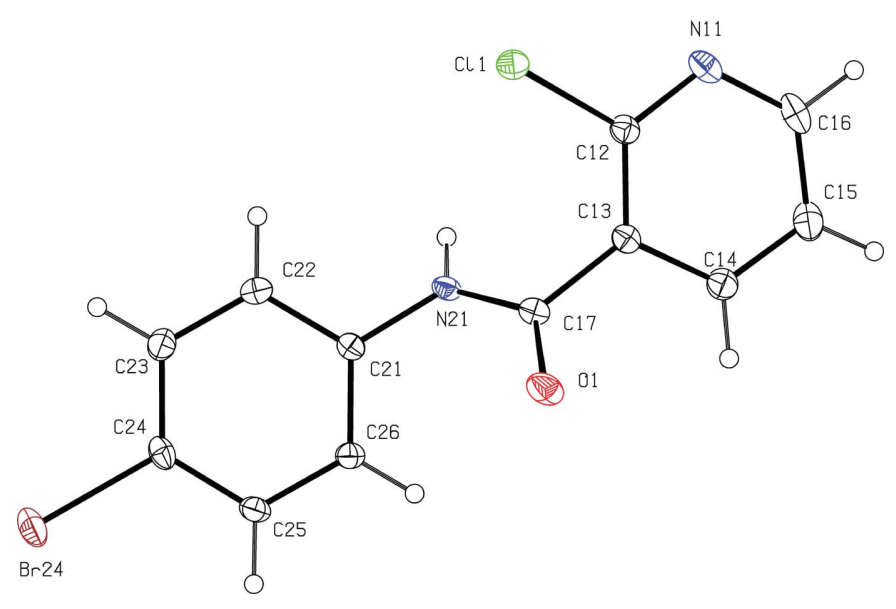

Figure 14

The molecule of $(\mathrm{V})$ showing the atom-labelling scheme. Displacement ellipsoids are drawn at the $30 \%$ probability level.

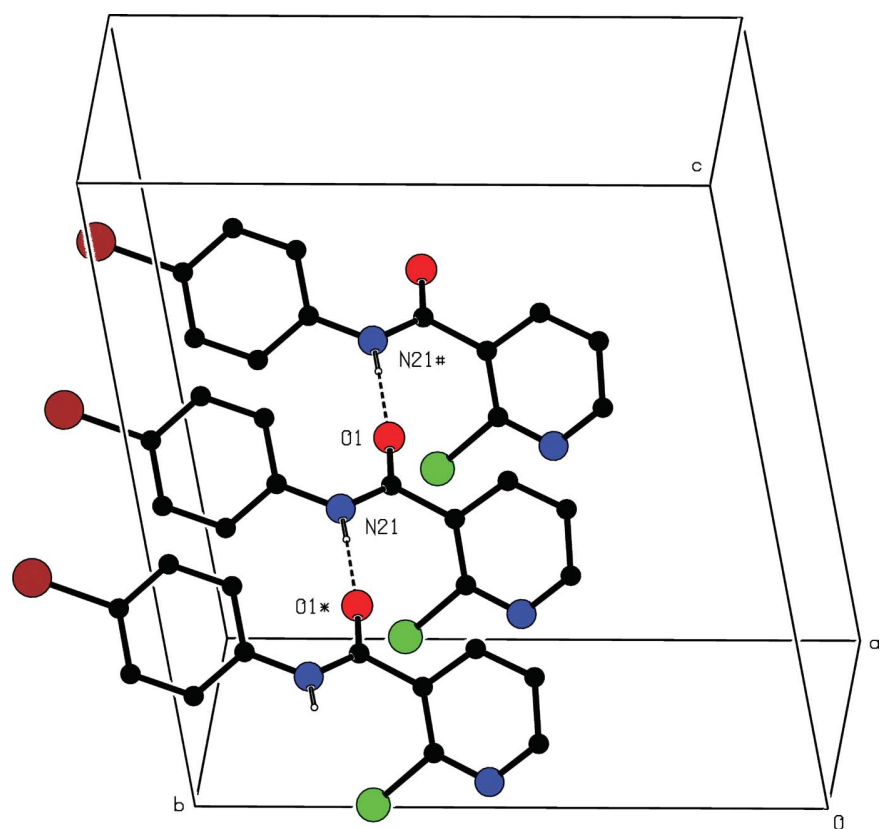

Figure 15

Part of the crystal structure of $(\mathrm{V})$ showing the formation of a hydrogenbonded $C(4)$ chain along [100]. For the sake of clarity, the $\mathrm{H}$ atoms bonded to $\mathrm{C}$ atoms have been omitted. The atoms marked with an asterisk $(*)$ or a hash (\#) are at the symmetry positions $(-1+x, y, z)$ and $(1+x, y, z)$, respectively. manner all the (010) sheets are linked into a continuous threedimensional array.

3.3.7. Compound (VII). The supramolecular aggregation of the 4-methoxyphenyl derivative, compound (VII) (Fig. 23), is exceptionally simple. A single $\mathrm{N}-\mathrm{H} \cdots \mathrm{O}$ hydrogen bond (Table 3 ) links the molecules into $C(4)$ chains generated by translation (Fig. 24). Four chain of this type pass through each unit cell, but there are no direction-specific interactions between adjacent chains: in particular, $\mathrm{C}-\mathrm{H} \cdots \pi$ (arene)

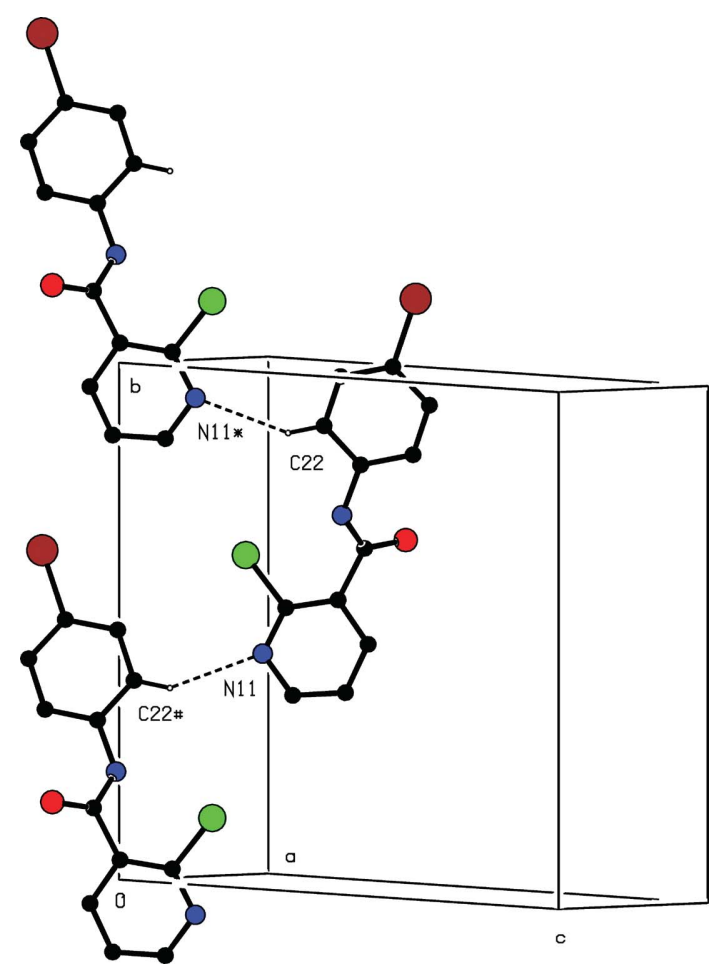

Figure 16

Part of the crystal structure of (V) showing the formation of a hydrogenbonded $C(8)$ chain along [010]. For the sake of clarity, the $\mathrm{H}$ atoms not involved in the motif shown have been omitted. The atoms marked with an asterisk $(*)$ or a hash (\#) are at the symmetry positions $\left(-x, \frac{1}{2}+y, \frac{1}{2}-z\right)$ and $\left(-x,-\frac{1}{2}+y, \frac{1}{2}-z\right)$, respectively.
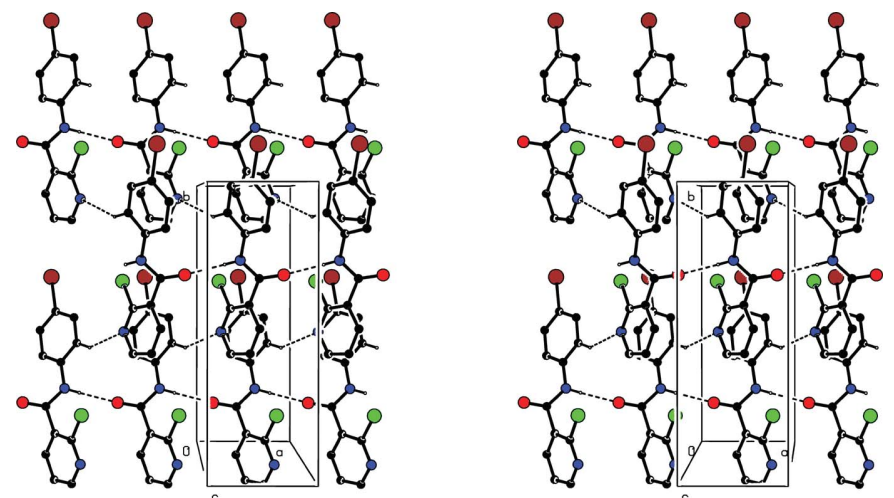

Figure 17

Stereoview of part of the crystal structure of $(\mathrm{V})$ showing the formation of a hydrogen-bonded (001) sheet of $R_{4}^{4}(22)$ rings. For the sake of clarity, the $\mathrm{H}$ atoms not involved in the motifs shown have been omitted. 


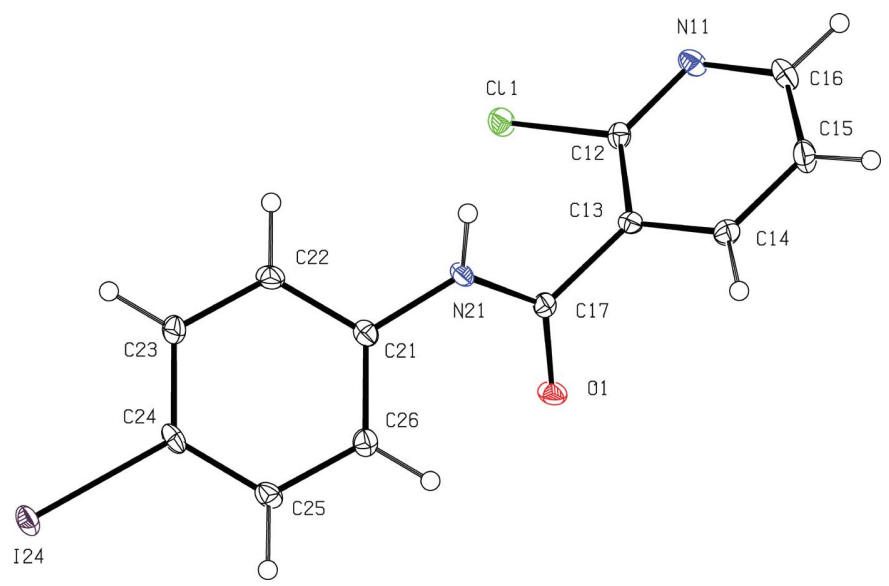

Figure 18

The molecule of (VI) showing the atom-labelling scheme. Displacement ellipsoids are drawn at the $30 \%$ probability level.

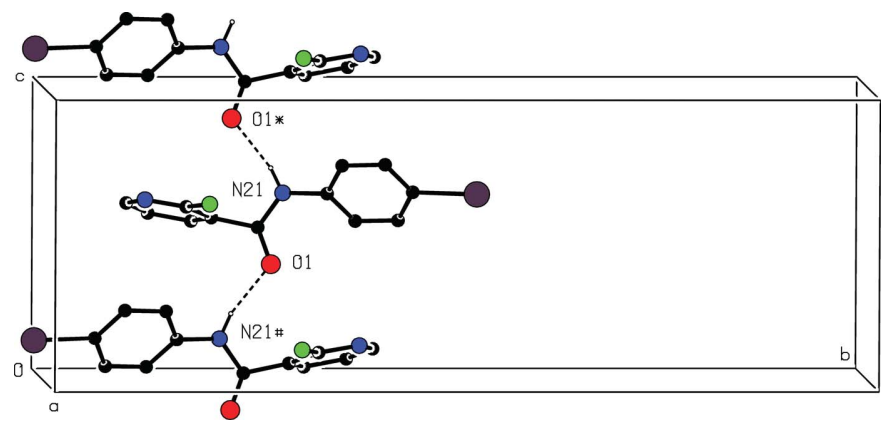

Figure 19

Part of the crystal structure of (VI) showing the formation of a hydrogenbonded $C(4)$ chain along [001]. For the sake of clarity, the $\mathrm{H}$ atoms bonded to $\mathrm{C}$ atoms have been omitted. The atoms marked with an asterisk $(*)$ or a hash (\#) are at the symmetry positions $\left(x, \frac{1}{2}-y, \frac{1}{2}+z\right)$ and $\left(x, \frac{1}{2}-y,-\frac{1}{2}+z\right)$, respectively.

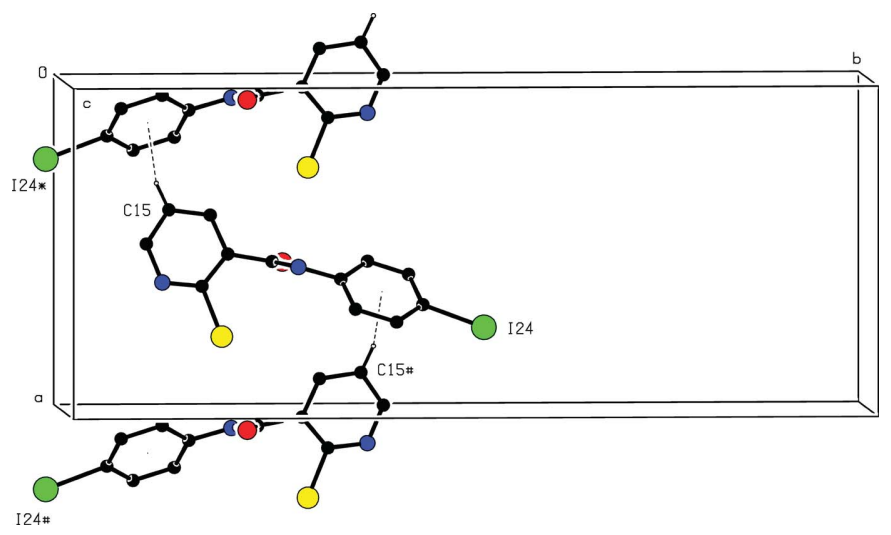

Figure 20

Part of the crystal structure of (VI) showing the formation of a hydrogenbonded chain along [100]. For the sake of clarity, the $\mathrm{H}$ atoms not involved in the motif shown have been omitted. The atoms marked with an asterisk $(*)$ or a hash (\#) are at the symmetry positions $\left(-\frac{1}{2}+x, \frac{1}{2}-y, 1-z\right)$ and $\left(\frac{1}{2}+x, \frac{1}{2}-y, 1-z\right)$, respectively. hydrogen bonds and aromatic $\pi \cdots \pi$ stacking interactions are both absent.

3.3.8. Compound (VIII). The structure of the 4-cyanophenyl compound (VIII) (Fig. 25) contains $\mathrm{N}-\mathrm{H} \cdots \mathrm{N}, \mathrm{C}-\mathrm{H} \cdots \mathrm{N}$ and $\mathrm{C}-\mathrm{H} \cdots \mathrm{O}$ hydrogen bonds (Table 3 ), as well as aromatic $\pi \cdots \pi$ stacking interactions; the resulting three-dimensional structure is of considerable complexity, although it is readily analysed in terms of its constituent one-dimensional substructures. Within the asymmetric unit, the amido N21 atom acts as a hydrogen-bond donor to the cyano N44 atom: similarly, the amido atom $\mathrm{N} 41$ at $(x, y, z)$ acts as a donor to the cyano $\mathrm{N} 24$ atom at $(-2+x, 1+y, z)$, so generating by translation a $C_{2}^{2}(16)$ chain running parallel to the $[2 \overline{1} 0]$ direc-
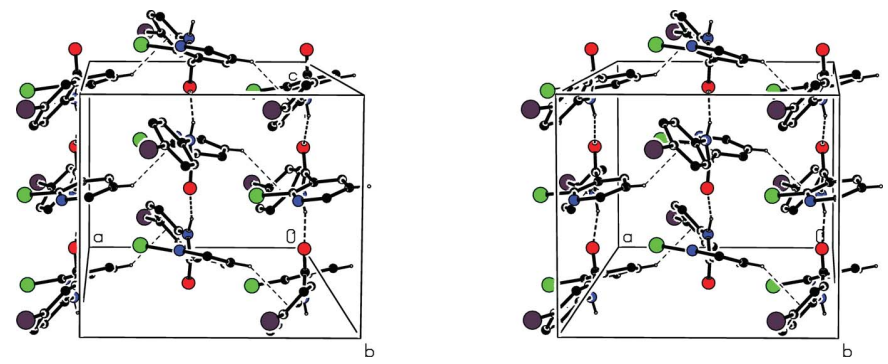

Figure 21

Stereoview of part of the crystal structure of (VI) showing the formation of a hydrogen-bonded (010) sheet. For the sake of clarity, the $\mathrm{H}$ atoms not involved in the motifs shown have been omitted.

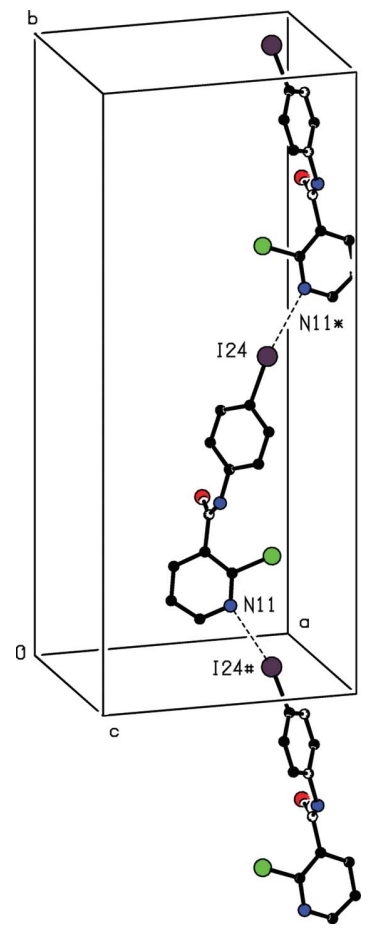

Figure 22

Part of the crystal structure of (VI) showing the formation of an iodo $\cdots \mathrm{N}$ (pyridyl) chain along [010]. For the sake of clarity, the $\mathrm{H}$ atoms have been omitted. The atoms marked with an asterisk (*) or a hash (\#) are at the symmetry positions $\left(\frac{3}{2}-x, \frac{1}{2}+y, z\right)$ and $\left(\frac{3}{2}-x,-\frac{1}{2}+y, z\right)$, respectively. 
tion (Fig. 26). In contrast to the simple chain generated by the hard hydrogen bonds, the soft hydrogen bonds generate both molecular ladders and chains of rings (Bernstein et al., 1995).

Atoms C15 and C35 in the bimolecular aggregate at $(x, y, z)$ act as hydrogen-bond donors respectively to atoms $\mathrm{O} 11$ and $\mathrm{O} 31$ in the aggregate at $(-1+x, y, z)$. The individual $\mathrm{C}-$ $\mathrm{H}$... O hydrogen bonds each generate by translation a $C(6)$ chain along [100] and, together with the $\mathrm{N}-\mathrm{H} \cdots \mathrm{N}$ hydrogen bond within the bimolecular aggregate, they generate a chain of edge-fused $R_{4}^{4}(32)$ rings (Fig. 27). Alternatively, this motif can be regarded as a molecular ladder, in which the $C(6)$

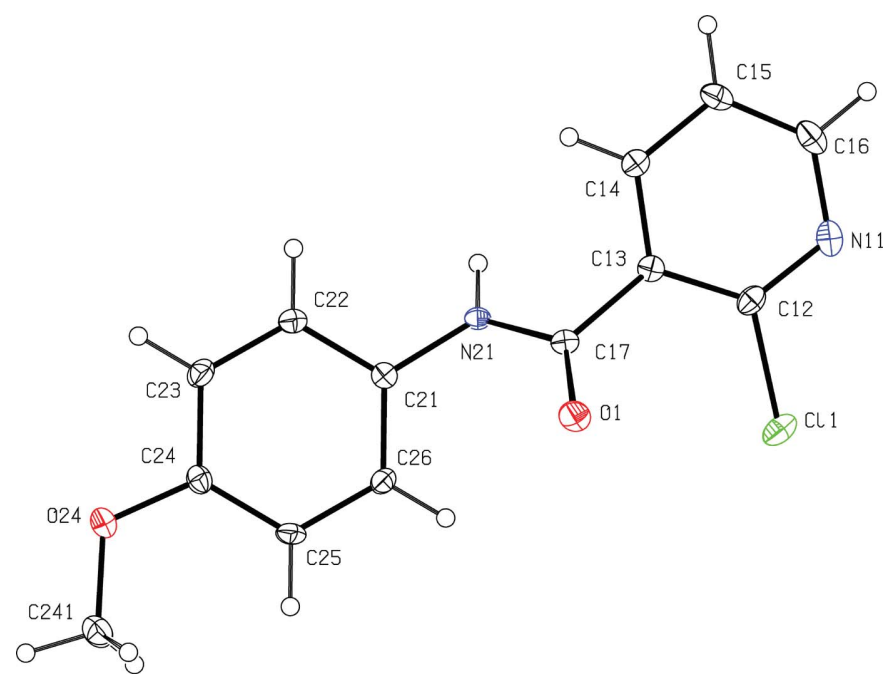

Figure 23

The molecule of (VII) showing the atom-labelling scheme. Displacement ellipsoids are drawn at the $30 \%$ probability level.

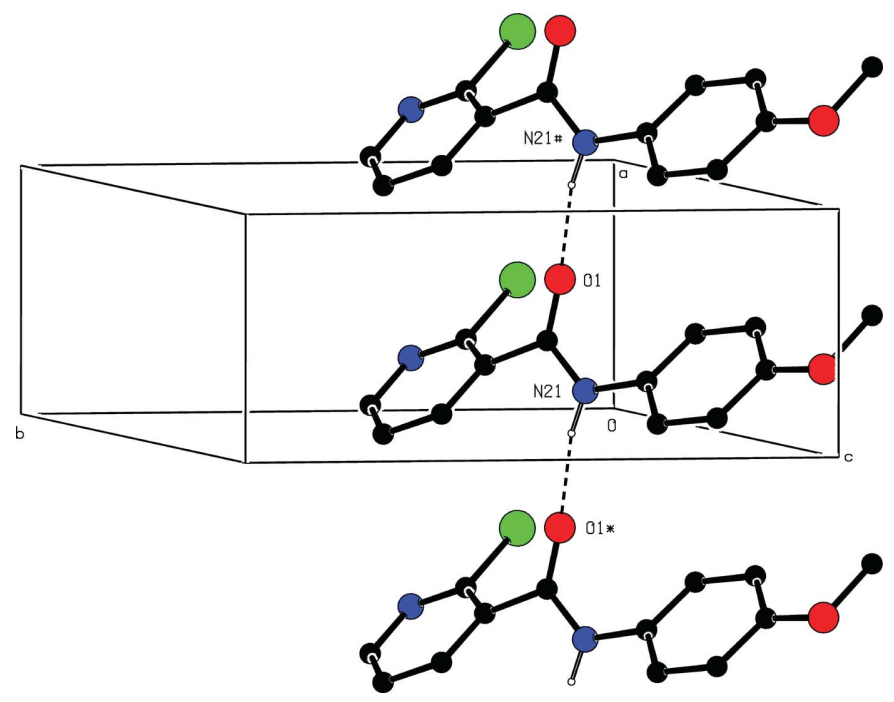

Figure 24

Part of the crystal structure of (VII) showing the formation of a hydrogen-bonded $C(4)$ chain along [100]. For the sake of clarity, the $\mathrm{H}$ atoms bonded to $\mathrm{C}$ atoms have been omitted. The atoms marked with an asterisk (*) or a hash (\#) are at the symmetry positions $(-1+x, y, z)$ and $(1+x, y, z)$, respectively. chains form the uprights, and $\mathrm{N}-\mathrm{H} \cdots \mathrm{N}$ hydrogen bonds form part of each rung.

In a similar way, the $\mathrm{C} 25$ and $\mathrm{C} 45$ atoms in the bimolecular aggregate at $(x, y, z)$ act as hydrogen-bond donors respectively to pyridyl atoms $\mathrm{N} 11$ and $\mathrm{N} 31$ in the aggregate at $(1+x,-1+y, z)$. The individual $\mathrm{C}-\mathrm{H} \cdots \mathrm{N}$ hydrogen bonds each generate by translation a $C(9)$ chain along [1ㅣㅣ and together with the $\mathrm{N}-\mathrm{H} \cdots \mathrm{N}$ hydrogen bond within the bimolecular aggregate they generate a chain of edge-fused $R_{4}^{4}(28)$ rings (Fig. 28). As before, this motif can be regarded as a molecular ladder, with the $C(9)$ chains now forming the uprights and with the $\mathrm{N}-\mathrm{H} \cdots \mathrm{N}$ hydrogen bonds in the rungs.

Finally, atoms $\mathrm{C} 14$ and $\mathrm{C} 34$ at $(x, y, z)$ acts as hydrogenbond donors respectively to atoms $\mathrm{O} 11$ at $(1-x,-y, 1-z)$ and $\mathrm{O} 31$ at $(-1-x, 1-y,-z)$, so generating two distinct $R_{2}^{2}(10)$ rings, both centrosymmetric, and centred respectively

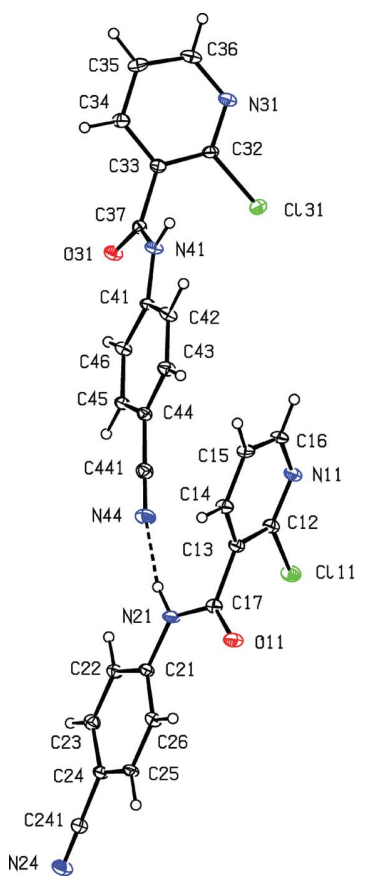

Figure 25

The two independent molecules of (VIII) showing the atom-labelling scheme and the $\mathrm{N}-\mathrm{H} \cdots \mathrm{N}$ hydrogen bond within the asymmetric unit. Displacement ellipsoids are drawn at the $30 \%$ probability level.
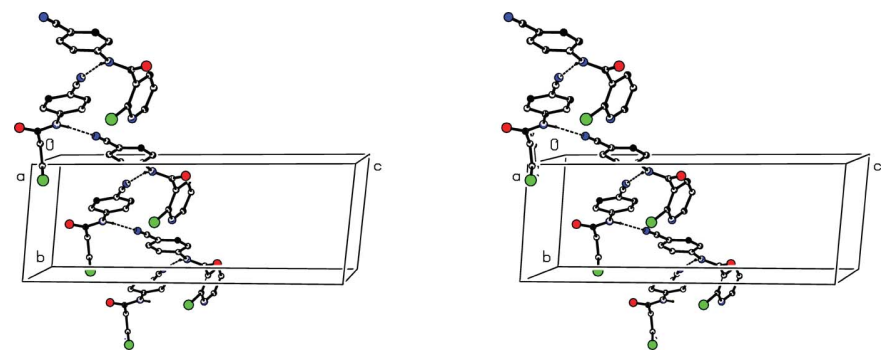

Figure 26

Stereoview of part of the crystal structure of (VIII) showing the formation of a $C_{2}^{2}(16)$ chain along [210] built from $\mathrm{N}-\mathrm{H} \cdots \mathrm{N}$ hydrogen bonds. For the sake of clarity, the $\mathrm{H}$ atoms bonded to $\mathrm{C}$ atoms have been omitted. 
at $\left(\frac{1}{2}, 0, \frac{1}{2}\right)$ and $\left(-\frac{1}{2}, \frac{1}{2}, 0\right)$. The combination of these two rings, together with the $\mathrm{N}-\mathrm{H} \cdots \mathrm{N}$ hydrogen bond within the asymmetric unit, then generates by inversion a chain of rings running parallel to the [21ㅣ] direction (Fig. 29). This chain, in turn, is reinforced by a combination of two $\pi \cdots \pi$ stacking interactions. The pyridyl rings containing N11 in the molecules are $(x, y, z)$ and $(1-x, 1-y, 1-z)$ and are parallel with an interplanar spacing of 3.426 (2) $\AA$; the ring-centroid separation is 3.589 (2) $\AA$, corresponding to a ring offset of 1.069 (2) $\AA$; similarly, the pyridyl rings containing N31 in the molecules at $(x, y, z)$ and $(-1-x, 2-y,-z)$ have an interplanar spacing of 3.334 (2) $\AA$, with a ring-centroid separation of 3.658 (2) $\AA$ and ring offset of 1.505 (2) $\AA$. These two interactions are centred across the inversion centres at $\left(\frac{1}{2}, \frac{1}{2}, \frac{1}{2}\right)$
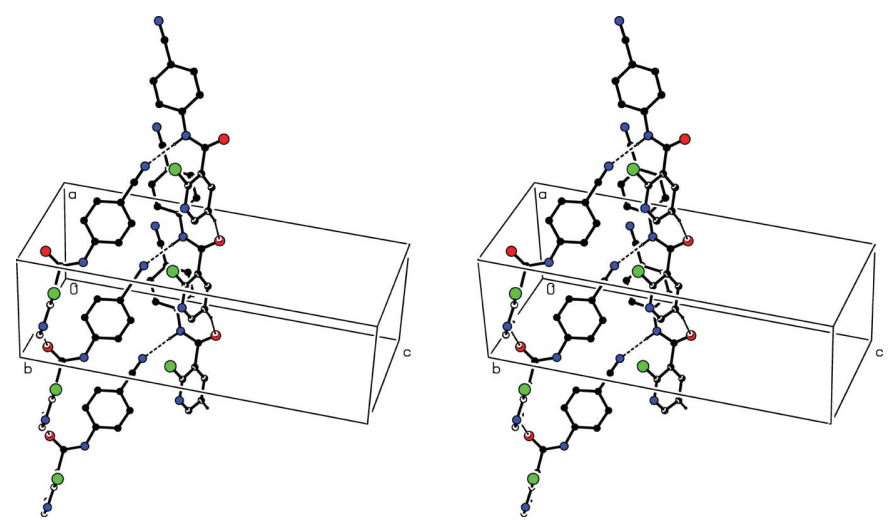

Figure 27

Stereoview of part of the crystal structure of (VIII) showing the formation of a chain of edge-fused $R_{4}^{4}(32)$ rings along [100] built from $\mathrm{N}-$ $\mathrm{H} \cdots \mathrm{N}$ and $\mathrm{C}-\mathrm{H} \cdots \mathrm{O}$ hydrogen bonds. For the sake of clarity, the $\mathrm{H}$ atoms bonded to $\mathrm{C}$ atoms, but not involved in the motif shown, have been omitted.
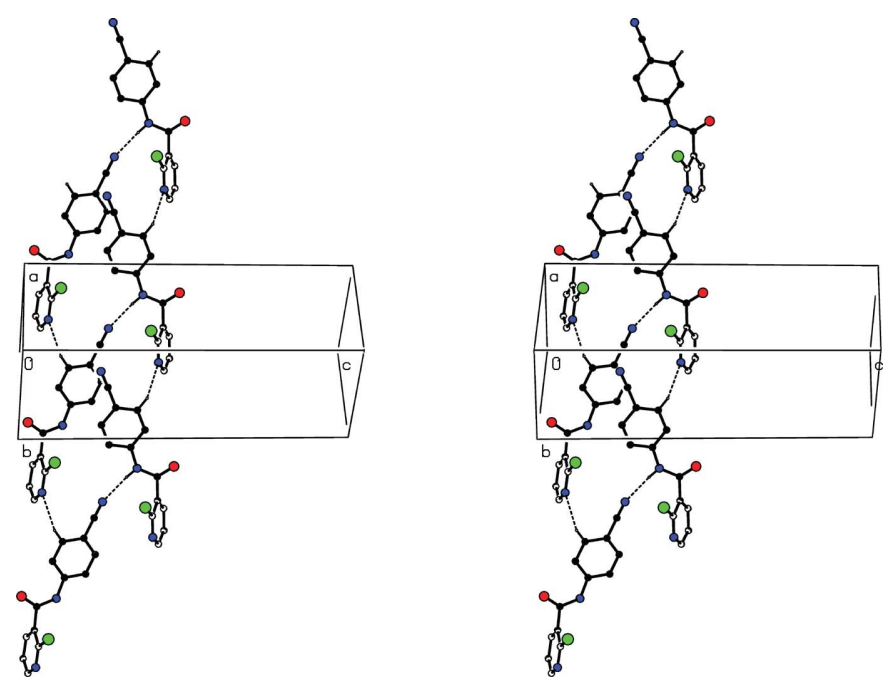

Figure 28

Stereoview of part of the crystal structure of (VIII) showing the formation of a chain of edge-fused $R_{4}^{4}(28)$ rings along [110] built from N$\mathrm{H} \cdots \mathrm{N}$ and $\mathrm{C}-\mathrm{H} \cdots \mathrm{N}$ hydrogen bonds. For the sake of clarity, the $\mathrm{H}$ atoms bonded to $\mathrm{C}$ atoms, but not involved in the motif shown, have been omitted. and $\left(-\frac{1}{2}, 1,0\right)$, respectively, and their combination thus generates a second [211] substructure (Fig. 30). The combi-

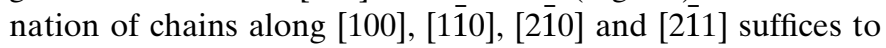
generate a continuous three-dimensional framework structure.

3.3.9. Compound (IX). The structure of the 4-nitrophenyl analogue (IX) has recently been described (de Souza et al., 2005) and here we briefly summarize its supramolecular behaviour. Compound (IX) crystallizes in the space group $P 2_{1} / n$ with $Z^{\prime}=2$, and the molecules are linked by two independent $\mathrm{N}-\mathrm{H} \cdots \mathrm{N}$ hydrogen bonds into $C_{2}^{2}(12)$ chains in which the two independent molecules alternate: however, the amidic $\mathrm{N}-\mathrm{H}$... O hydrogen bonds which characterize (II)(VIII), although not (I), are absent from the structure of (IX).

3.3.10. General comments on the structures. Although the approximately isosteric requirements of methyl and chloro substituents on aryl rings often lead to the isomorphism of corresponding pairs of compounds, the unit-cell dimension and $Z^{\prime}$ values (Table 1$)$ for (II) $\left(X=\mathrm{CH}_{3}\right)$ and (IV) $(X=\mathrm{Cl})$ here are entirely distinct. Likewise, the four 4-halogenophenyl derivatives (III)-(VI) all crystallize in different space groups, one triclinic, two monoclinic and one orthorhombic. In contrast to this, we have recently observed:

(i) that the 4-substituted anilinium 2-carboxy-4-nitrobenzoates [4- $\left.\mathrm{XC}_{6} \mathrm{H}_{4} \mathrm{NH}_{3}\right]^{+} \cdot\left[\mathrm{C}_{8} \mathrm{H}_{4} \mathrm{NO}_{6}\right]^{-}$, for $X=\mathrm{H}, \mathrm{Cl}, \mathrm{Br}$ and $\mathrm{I}$, are all isomorphous and approximately isostructural (Glidewell et al., 2005);

(ii) that a series of cyclopenta $[g]$ pyrazolo[1,5- $a]$ pyrimidines carrying 4-methylphenyl, 4-chlorophenyl or 4-bromophenyl substituents are all strictly isostructural (Portilla et al., 2005); and
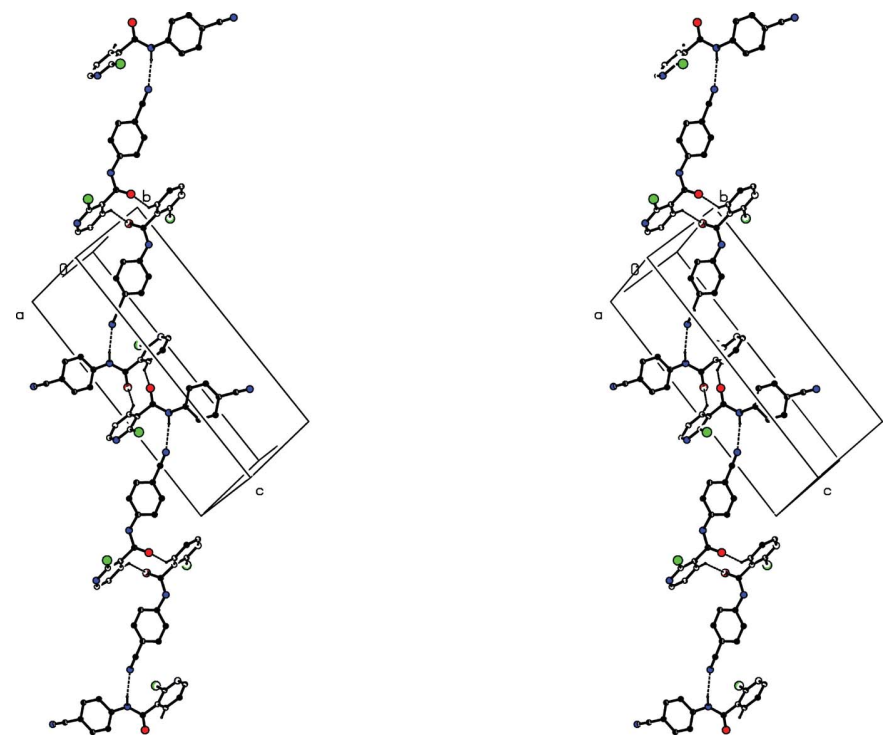

Figure 29

Stereoview of part of the crystal structure of (VIII) showing the formation of a chain of $R_{2}^{2}(10)$ rings along [2i11] built from $\mathrm{N}-\mathrm{H} \cdots \mathrm{N}$ and $\mathrm{C}-\mathrm{H} \cdots \mathrm{O}$ hydrogen bonds. For the sake of clarity, the $\mathrm{H}$ atoms bonded to $\mathrm{C}$ atoms, but not involved in the motif shown, have been omitted. 
(iii) that a pair of benzo[f]pyrazolo[3,4-b]quinolines carrying 4-chlorophenyl or 4-bromophenyl substituents are also strictly isostructural (Serrano et al., 2005a,b).

As the single substituent in the aryl ring is varied within the series (I)-(IX), so too are the direction-specific intermolecular interactions which are manifested in the supramolecular structures. A very common supramolecular motif found in the crystal structures of simple amides is the formation of simple $C$ (4) chains built from $\mathrm{N}-\mathrm{H} \cdots \mathrm{O}$ hydrogen bonds, with corresponding $C_{2}^{2}(8)$ chains in some cases where $Z^{\prime}=2$. Such chains occur in (II), where the chain is of $C_{2}^{2}(8)$ type; in (IV), where there are four independent $C(4)$ chains, and in (V), (VI) and (VII), each of which forms a single $C(4)$ chain. It is striking how readily this motif can be disrupted when alternative hydrogen-bond acceptor sites are available, so that the amidic $\mathrm{N}-\mathrm{H}$ donor has a pyridyl $\mathrm{N}$ acceptor in each of (I), (VIII) and (IX), while in (III) the water $\mathrm{O}$ atom acts as the acceptor to form the amidic $\mathrm{N}-\mathrm{H}$ bond (Table 3 ). Despite the acceptor role for the pyridyl $\mathrm{N}$ atom manifested in (I), (VIII) and (IX), this potential acceptor is completely inactive in each of (II), (IV) and (VI), while in (III) and (V) this site acts as the acceptor in $\mathrm{O}-\mathrm{H} \cdots \mathrm{N}$ and $\mathrm{C}-\mathrm{H} \cdots \mathrm{N}$ hydrogen bonds, respectively. No obvious pattern of behaviour can be discerned here and any attempt to rationalize such behaviour would necessarily be largely, if not entirely, speculative: in this connection, it should perhaps be emphasized that the intermolecular forces involved here are all fairly weak and soft, and not readily susceptible to quantitative modelling.

For (IV), where $X=\mathrm{Cl}$, (VII) where $X=\mathrm{OMe}$ and (IX) where $X=\mathrm{NO}_{2}$ (de Souza et al., 2005), the supramolecular structures are all one-dimensional, with isolated chains built from $\mathrm{N}-\mathrm{H} \cdots \mathrm{O}$ hydrogen bonds in (VII), similar chains linked in pairs by $\mathrm{C}-\mathrm{H} \cdots \pi$ (arene) hydrogen bonds in (IV), and chains built from $\mathrm{N}-\mathrm{H} \cdots \mathrm{N}$ hydrogen bonds in (IX). Compounds (IV) and (IX) differ further in that (IV), where $Z^{\prime}=4$, contains four independent chains, each containing a single molecular type, whereas (IX), where $Z^{\prime}=2$, contains a single chain where the two independent molecules alternate.
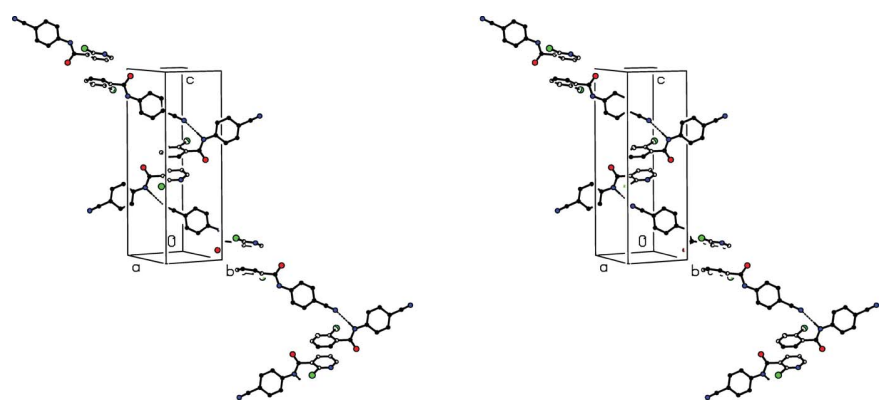

Figure 30

Stereoview of part of the crystal structure of (VIII) showing the formation of a $\pi$-stacked chain along [2i11]. For the sake of clarity, the $\mathrm{H}$ atoms have been omitted.<smiles>O=C(Nc1ccccc1[N+](=O)[O-])c1cccnc1Cl</smiles>

$(\mathrm{X})$<smiles>O=C(Nc1ccc(Br)cc1)c1cccnc1</smiles>

(XIII)<smiles>N#CC(=O)c1cccnc1</smiles>

$(\mathrm{XV})$

The structures of compounds (I), where $X=\mathrm{H}$, (II), where $X=\mathrm{Me}$, (III), where $X=\mathrm{F}$, and (V), where $X=\mathrm{Br}$, are all twodimensional. $\mathrm{N}-\mathrm{H} \cdots \mathrm{N}$ hydrogen bonds are present only in the structure of (I); $\mathrm{C}-\mathrm{H} \cdots \mathrm{O}$ and $\mathrm{C}-\mathrm{H} \cdots \pi$ (arene) hydrogen bonds are present only in the structure of (II); O$\mathrm{H} \cdots \mathrm{O}$ and $\mathrm{O}-\mathrm{H} \cdots \mathrm{N}$ hydrogen bonds, and aromatic $\pi \cdots \pi$ stacking interactions are present only in the structure of (III); and $\mathrm{C}-\mathrm{H} \cdots \mathrm{N}$ hydrogen bonds are present only in the structure of $(\mathrm{V})$. For the two compounds with three-dimensional supramolecular structures, there are no directionspecific intermolecular interactions in common: the structure of (VI), where $X=\mathrm{I}$, is built from $\mathrm{N}-\mathrm{H} \cdots \mathrm{O}$ and $\mathrm{C}-$ $\mathrm{H} \cdots \pi$ (arene) hydrogen bonds, and iodo $\cdots$ pyridyl interactions, while the structure of (VIII), where $X=\mathrm{CN}$, is built from $\mathrm{N}-\mathrm{H} \cdots \mathrm{N}, \mathrm{C}-\mathrm{H} \cdots \mathrm{N}$ and $\mathrm{C}-\mathrm{H} \cdots \mathrm{O}$ hydrogen bonds.

3.3.11. Compounds closely related to (I)-(IX). Here we briefly comment on the supramolecular structures of some closely related compounds, including two isomers $(\mathrm{X})$ and (XI) of (IX) (de Souza et al., 2005), and (XII)-(XV) retrieved from the Cambridge Structural Database (CSD; Allen, 2002).

In $(\mathrm{X})$, the only $\mathrm{N}-\mathrm{H} \cdots \mathrm{O}$ hydrogen bond is intramolecular, so that again the formation of a $C(4)$ chain has readily been prevented: the molecules of $(\mathrm{X})$ are linked into chains of centrosymmetric edge-fused $R_{2}^{2}(14)$ and $R_{4}^{4}(24)$ rings by two independent $\mathrm{C}-\mathrm{H} \cdots$. O hydrogen bonds, while the pyridyl $\mathrm{N}$ atom is inactive as an acceptor. In the isomeric compound 
(XI), which unexpectedly crystallizes as a stoichiometric monohydrate just like compound (III), the amidic $\mathrm{N}-\mathrm{H}$ bond acts as a hydrogen-bond donor to the water molecule, and these bimolecular aggregates are linked by a combination of $\mathrm{O}-\mathrm{H} \cdots \mathrm{N}$ and $\mathrm{O}-\mathrm{H} \cdots \mathrm{O}$ hydrogen bonds to form a chain of edge-fused rings containing two different types of $R_{4}^{4}(16)$ ring. Thus, despite the different composition and constitutions of (III) and (XI), their supramolecular aggregation patterns show a considerable degree of similarity.

The unsubstituted amide (XII) (CSD code PYDCXA10; Gdaniec et al., 1979), which may be regarded as the parent compound for this whole series, forms simple $\mathrm{C}(4)$ chains built from $\mathrm{N}-\mathrm{H} \cdots \mathrm{O}$ hydrogen bonds, and these chains are linked in pairs by a centrosymmetric $\pi \cdots \pi$ stacking interaction. In the dichloro compound (XIII) (CSD code HIFWUO; Jethmalani et al., 1996), a combination of $\mathrm{N}-\mathrm{H} \cdots \mathrm{N}$ and $\mathrm{C}-$ $\mathrm{H} \cdots \mathrm{N}$ hydrogen bonds generates a $C(3) C(6)\left[R_{2}^{1}(7)\right]$ chain of rings, but no $\mathrm{N}-\mathrm{H} \cdots \mathrm{O}$ hydrogen bonds are present.

The ease with which the $C(4)$ motif can be disrupted, not only by the presence of water molecules in the structure, but also by intramolecular hydrogen bonds, is shown both by $(\mathrm{X})$, and by (XIV) (CSD code MURWUR; Zhang et al., 2002) and (XV) (CSD code ZIKWEX; Pèpe et al., 1995), where the amidic $\mathrm{N}-\mathrm{H}$ bonds participate respectively in intramolecular $\mathrm{N}-\mathrm{H} \cdots \mathrm{N}$ and $\mathrm{N}-\mathrm{H} \cdots \mathrm{O}$ hydrogen bonds. The supramolecular structure of (XIV) consists of simple $C(6)$ chains built from $\mathrm{C}-\mathrm{H} \cdots \mathrm{O}$ hydrogen bonds, while the structure of $(\mathrm{XV})$ consists of effectively isolated molecules with no directionspecific intermolecular interactions of any kind.

\section{Concluding remarks}

The variations in the unit-cell dimensions in (I)-(IX) and the consequent absence of any isomorphisms, together with the very wide variations in the active intermolecular interactions and in the resulting supramolecular structures, both for these compounds and for the related compounds $(\mathrm{X})-(\mathrm{XV})$, raise the question of whether supramolecular structures of this type, dependent on weak intermolecular forces, are likely to become reliably predictable in the foreseeable future.

We thank the EPSRC National Crystallography Service, University of Southampton, UK, for collecting the X-ray data for (I) and (III)-(VIII). Data for (II) were collected on
Daresbury SRS Station 9.8, for which we thank the EPSRCfunded synchrotron crystallography service and Professor W. Clegg. JLW and SMSVW thank CNPq and FAPERJ for financial support.

\section{References}

Allen, F. H. (2002). Acta Cryst. B58, 380-388.

Bernstein, J., Davis, R. E., Shimoni, L. \& Chang, N.-L. (1995). Angew. Chem. Int. Ed. Engl. 34, 1555-1573.

Bruker (2004). APEX2, SADABS and SAINT, Version 6.02a. Bruker AXS Inc., Madison, Wisconsin, USA.

Cernik, R. J., Clegg, W., Catlow, C. R. A., Bushnell-Wye, G., Flaherty, J. V., Greaves, G. N., Hamichi, M., Burrows, I., Taylor, D. J. \& Teat, S. J. (1997). J. Synchrotron Rad. 4, 279-286.

Ferguson, G. (1999). PRPKAPPA. University of Guelph, Canada.

Flack, H. D. (1983). Acta Cryst. A39, 876-881.

Gdaniec, M., Jaskolski, M. \& Kosturkiewicz, Z. (1979). Pol. J. Chem. $\mathbf{5 3}, 2563-2569$.

Glidewell, C., Low, J. N., Skakle, J. M. S. \& Wardell, J. L. (2005). Acta Cryst. C61, o276-0280.

Hooft, R. W. W. (1999). Collect. Nonius BV, Delft, The Netherlands. Jethmalani, J. M., Camp, A. G., Soman, N. G., Hawley, J. W., Setliff, F. L. \& Holt, E. M. (1996). Acta Cryst. C52, 438-441.

McArdle, P. (2003). OSCAIL for Windows, Version 10. Crystallography Centre, Chemistry Department, NUI Galway, Ireland.

Otwinowski, Z. \& Minor, W. (1997). Methods in Enzymology, Vol. 276, Macromolecular Crystallography, Part A, edited by C. W. Carter Jr \& R. M. Sweet, pp. 307-326. New York: Academic Press.

Pèpe, G., Pfefer, G. \& Boistelle, R. (1995). Acta Cryst. C51, 26712672.

Portilla, J., Quiroga, J., Cobo, J., Low, J. N. \& Glidewell, C. (2005). Acta Cryst. C61, o452-o456.

Serrano, H., Quiroga, J., Cobo, J., Low, J. N. \& Glidewell, C. (2005a). Acta Cryst. E61, o1058-o1060.

Serrano, H., Quiroga, J., Cobo, J., Low, J. N. \& Glidewell, C. (2005b). Acta Cryst. E61, o1702-o1703.

Sheldrick, G. M. (1997a). SHELXS97 University of Göttingen, Germany.

Sheldrick, G. M. (1997b). SHELXL97. University of Göttingen, Germany.

Sheldrick, G. M. (2003). SADABS, Version 2.10. University of Göttingen, Germany.

Souza, M. V. N. de, Vasconcelos, T. R. A., Wardell, S. M. S. V., Wardell, J. L., Low, J. N. \& Glidewell, C. (2005). Acta Cryst. C61, o204-o208. Spek, A. L. (2003). J. Appl. Cryst. 36, 7-13.

Starbuck, J., Norman, N. C. \& Orpen, A. G. (1999). New J. Chem. 23, 969-972.

Wilson, A. J. C. (1976). Acta Cryst. A32, 994-996.

Zhang, J.-Y., Tu, C., Lin, J., Fun, H.-K., Chantrapromma, S., You, X.-Z. \& Guo, Z.-J. (2002). Chin. J. Inorg. Chem. 18, 554-558. 